\title{
Supersonic Crossflow Transition Control in Ground and Flight Tests
}

\author{
Lewis R. Owens, ${ }^{1}$ George B. Beeler, ${ }^{2}$ Rudolph A. King, ${ }^{3}$ Amanda Chou, ${ }^{4}$ and Ponnampalam Balakumar ${ }^{5}$ \\ NASA Langley Research Center, Hampton, VA, 23681, United States \\ and \\ Daniel W. Banks ${ }^{6}$ \\ NASA Armstrong Flight Research Center, Edwards, CA, 93523, United States
}

\begin{abstract}
This paper describes the use of distributed-roughness-element (DRE) patterns along a Mach 2 design swept-wing leading edge to increase the laminar flow extent and thereby reduce drag. One swept-wing model was tested in a supersonic wind tunnel as well as beneath a supersonic flight vehicle. Wing model surface data acquired during these tests included pressures, temperatures, and boundary-layer transition locations. Similarities and differences in experimental results are discussed. While wind tunnel and flight results show some differences, the wind tunnel results still provide key insights necessary for understanding how to design effective DRE patterns for use in flight applications. Experimental results demonstrate a DRE flow control effect observed in flight similar to that observed in the wind tunnel. Finally, a different perspective is discussed concerning what flow control role the DRE patterns might perform in any future swept-wing laminar flow control applications.
\end{abstract}

\section{Introduction}

Envision flying faster than the speed of sound and being bold enough to continue accelerating toward Mach 2. Imagine traversing continents and oceans in about half the time it takes for a typical subsonic commercial airliner today. This flight capability, though inefficient, currently exists primarily for limited use by military pilots, test pilots, and astronauts. No such romanticized experience yet exists for the civilian populations of the world. Interestingly, the latter third of the $20^{\text {th }}$ century included a brief period in which commercial supersonic flight was available to a select few civilians who possessed the means to access expensive seats onboard either the Franco-British Concorde or the Russian Tupolev Tu-144 (current world record holder as the fastest airliner). A flying U.S. commercial supersonic transport is notably absent from this elite list of engineering marvels. These supersonic transports were proven to be economically nonviable due to technology limitations. Takeoff and landing noise levels were too high and the sonic booms disturbed any community near the vehicle flight path. This led to regulations to limit flight paths to overwater routes. The available engine technology was also not fuel-efficient. All these factors combined to produce an aircraft system with a very small market for the rich and famous.

The NASA Advanced Air Vehicles Program has continued research activities exploring potential supersonic design technologies to address specific technical challenges associated with sonic boom reduction (community response and public policy on overland flight), environmental concerns (takeoff/landing noise levels and high-altitude emissions), as well as cruise efficiency (fuel consumption and drag reduction). Decades of sonic-boom reduction research [1] suggest properly shaped supersonic aircraft could potentially travel overland without negatively impacting nearby communities. Sonic boom research with improved vehicle shaping will provide community response data. These data will be considered by U.S. and international regulators to determine if changes to supersonic overland flight policy is warranted.

Assuming this sonic-boom technology challenge is met, new supersonic aircraft designers will need to deal with other technological barriers. Cruise efficiency requirements will certainly be met through both fuel-efficient engine

${ }^{1}$ Aerospace Engineer, Flow Physics \& Control Branch, AIAA Senior Member.

${ }^{2}$ Aerospace Engineer, Flow Physics \& Control Branch, AIAA Senior Member.

${ }^{3}$ Aerospace Engineer, Flow Physics \& Control Branch, AIAA Member.

${ }^{4}$ Aerospace Engineer, Flow Physics \& Control Branch, AIAA Senior Member.

${ }^{5}$ Aerospace Engineer, Flow Physics \& Control Branch, AIAA Associate Fellow.

${ }^{6}$ Aerospace Engineer, Aerodynamics \& Propulsion Branch, AIAA Associate Fellow. 
technologies as well as aerodynamic drag-reduction technologies. An opportunity for drag reduction includes minimizing the skin-friction drag on major aircraft components. Creating a potential for laminar-flow boundary layers over wings, fuselages, and other surfaces is one option being considered. Like sonic-boom research, there have been many decades of laminar flow research $[2,3]$. The primary methods advanced to promote laminar flow include passively controlling pressure distributions on surfaces through wing shaping (natural laminar flow or NLF) and adding porous suction panels for active boundary-layer flow control. This type of hybrid laminar-flow control (HLFC) system was experimentally tested during the NASA High-Speed Research program in the 1990s [4]. This application achieved large laminar flow regions on the wing of the modified F-16XL. Unfortunately, the impressive extent of laminar flow created appeared not to outweigh the concerns about additional weight, maintenance, and reliability associated with this type of active flow control system.

While this HLFC research was occurring, academic research was exploring swept-wing flow physics to understand the relevant boundary-layer transition mechanisms. In the 1990s and early 2000s, Professor W. S. Saric and his colleagues began to study low Reynolds number, subsonic swept wings in low-disturbance wind tunnels [5-11]. From these studies, they discovered that certain distributed arrays of micron-sized roughness elements placed near the boundary-layer stability neutral point for the most-amplified stationary crossflow wavelength would extend the laminar flow regions. They called these roughness arrays distributed roughness elements (DREs). As their DRE research studies advanced, the push to demonstrate the DRE flow control concept at higher Reynolds numbers corresponding to subsonic flight conditions drove them to develop a flight research lab at Texas A \& M University [12]. Results from these subsonic flight studies were initially promising, but inconsistency and nonrepeatability issues led to questions about the viability of the DRE flow control technique at higher Reynolds number subsonic flight conditions [13-15]. Other crossflow research also explored the DRE flow control concept in subsonic and supersonic tunnels [16,17], supersonic flight [18], and computational supersonic swept-wing crossflow boundary-layer receptivity studies $[19,20]$.

Our swept-wing laminar flow research began with a preliminary study to develop an approach to assess boundarylayer transition due to crossflow transition mechanisms in the NASA Langley Research Center (LaRC) 20-Inch Supersonic Wind Tunnel (SWT) [21,22]. After establishing a viable assessment approach, we turned our attention to the task of designing a more sophisticated, highly-swept wing model capable of being tested in SWT and on the NASA Armstrong Flight Research Center (AFRC) F-15B Centerline Instrumented Pylon (CLIP) test fixture [23-25]. This strategy provided a rare opportunity to compare boundary-layer transition research results on the same wing model in both wind tunnel and flight experiments. Each test environment has its own systematic biases and the approach we used to understand these biases is illustrated in Fig. 1. In this paper, we present an overview of the significant findings from our study by describing the similarities and differences between results obtained in these three test environments. In an effort to bridge the technology gap between basic and applied research, we also evaluated a flow control technology with potential to promote laminar flow on swept wings to reduce skin-friction drag. The insights gained from our research to make DRE patterns effective for supersonic flow conditions are also described.

\section{Experimental Description}

\section{A. Swept-Wing Model}

During the initial boundary-layer transition research planning, our program sponsors challenged us to consider a wing model geometry more representative of a supersonic transport and not the more popular wind tunnel transition research geometries (flat plates and cones). Even so, we kept the wing geometry as simple as possible for easier modeling in CFD while still capturing relevant supersonic wing leading-edge flow physics. Ideally, transition research is conducted in low-disturbance wind tunnels with turbulence intensities of about $0.05 \%$, but model size and Mach constraints contributed to our decision to use a conventional supersonic facility, the LaRC 20-Inch Supersonic Wind Tunnel (SWT). During previous swept-wing research in SWT [21], we measured freestream mass-flux turbulence levels of about $0.1 \%$. These fluctuation levels are considered low enough to enable investigation of crossflow transition mechanisms in this tunnel, but these levels are expected to be higher than those in flight. Inflight measurements of turbulence levels under the F-15B are still needed at supersonic flight test conditions to confirm this belief.

The tunnel and flight test conditions (assuming a standard atmospheric model) targeted in this research are shown in Fig. 2. The filled circle symbols indicate the range of primary conditions tested in SWT and the red arrow shows the overlapping flight test range. The design condition selected for this wing model was $M=2$ at a unit $\operatorname{Re}=11.6$ million $/ \mathrm{m}$ (open green circle symbol). The lower Reynolds number conditions available in the tunnel test corresponded to higher altitudes where the pilots required pressure suits. However, the pressure suit system was not available for the test aircraft during this flight test so these lower Reynolds number conditions were not explored in flight. 
We performed inviscid simulations on various $65^{\circ}$ swept-wing model concepts inside an open-ended box representing the tunnel walls using FUN3D [26]. These simulations were designed to better understand the relationship between model sizing and shock reflection interactions with the model flow in the tunnel, thus guiding the selection of a model planform and size suitable for the $\mathrm{M}=2$ flow conditions in the SWT test section. The chosen maximum wing model streamwise root chord is $556.8 \mathrm{~mm}$ to minimize interactions with the reflected wing leading-edge shock. We refined this wing airfoil geometry using viscous FUN3D wing-model simulations with inviscid tunnel walls. Figure 3 provides a representative set of streamwise mass-flux and crossflow boundary-layer profiles indicative of the degree of uniform 3-D leading-edge flow predicted across the finite span $(266.7 \mathrm{~mm})$ of this wing-model design. Thirty boundary-layer profiles were extracted from these viscous flow results along each of three span stations up to the maximum wing thickness location. These profiles were input into a boundary-layer stability analysis using a Linear Stability Theory (LST) approach to predict the disturbance growth for the most-amplified stationary crossflow (SCF) wavelength. We chose a disturbance amplification factor $(\mathrm{N}=5.5$ for a most-amplified SCF wavelength of $3 \mathrm{~mm}$ at $\mathrm{M}=2$ and a unit $\mathrm{Re}=11.6 \mathrm{million} / \mathrm{m}$ design condition) to predict the expected laminar flow extent based upon our earlier $35^{\circ}$ swept-wing experimental transition results in SWT [21].

Increasing the constant maximum airfoil section thickness produced an increase in the favorable streamwise pressure gradient thus promoting a stronger crossflow environment for earlier boundary-layer transition. Details on the final model wing design geometry including the airfoil section along a full normal chord and the planform are shown in Fig. 4. In Fig. 4c, the predicted SCF transition fronts are shown (open circle with dashed lines) to illustrate how increasing the maximum thickness-to-root-chord ratio from $5 \%$ to $7 \%$ moves the transition front from just downstream of the wing leading-edge part line to just ahead of it. We decided to use the greater wing maximum thickness of $37.8 \mathrm{~mm}$ (Fig. 4b) to give the wing leading-edge flow control enough area ahead of the maximum thickness to promote laminar flow. Our concern here lay in the uncertainty in predicting the natural laminar flow extent. If our design produced a greater laminar flow extent in the experiments than predicted, then there may not be an opportunity to demonstrate any flow control effect (i.e., transition delay) on the wing model.

The wing leading-edge radius was chosen to prevent attachment-line contamination/instability growth. Isolating the crossflow transition mechanism required the attachment-line Reynolds number $\left(\operatorname{Re}_{\theta}\right)$ to be less than about 100 . For the range of conditions tested in the tunnel and flight (Fig. 2), the attachment-line Reynolds number falls within a narrow range (20-30) with a $0.254 \mathrm{~mm}$ leading-edge radius (Fig. $4 \mathrm{a}$ ) blended into the biconvex airfoil section using a tangent parabolic fit. There is some disadvantage to using such a small wing leading-edge radius. This small radius makes the wing leading edge more susceptible to flow separation rendering the applied flow control ineffective. Viscous flow calculations were performed on the final wing model geometry at several angles of attack to determine how sensitive this design is to misalignment with the freestream. The predictions (pressure contours and streamlines) from this angle-of-attack study shown in Fig. 5 suggest the wing leading edge can handle between 1 to 2 degrees of flow misalignment before the outboard leading-edge flow undergoes any flow separation. Also note the separated flow predicted in the wing trailing-edge region. This particular flow separation is caused by the reflected leading-edge shock from the tunnel side wall and is not predicted for the flight setup.

The wing model incorporated instrumentation (Fig. 4c) to characterize the wing flow boundary conditions in each test environment. Ten static pressure orifices were installed along a full normal chord section near the wing tip on both sides of the model, 20 pressures in total. These pressure orifices were located downstream of the primary laminar flow control region of interest to prevent accidentally tripping the leading-edge boundary layer while also not getting too close to the wing-tip separated flow region. Inboard of these static pressures, 16 subsurface thermocouples are located along a full normal chord section on both sides of the model, 32 temperatures in total.

The wing model system includes four interchangeable wing leading-edge parts. One wing leading edge was painted matte black to match the main wing-body for compatibility with the flight infrared (IR) thermography data acquisition system. The painted wing model also provided good contrast background for the sublimating chemical technique used in SWT because the IR test technique was not available during this phase of the tunnel research. Another wing leading edge was unpainted and contained an instrument pocket with several blank cover plates. Two cover plates were each modified to accommodate five, flush-mounted custom unscreened Kulite transducers to measure unsteady static pressures. These unsteady pressure data were acquired in both the tunnel and flight tests, but are still being analyzed and will not be presented in this paper.

Sample surface roughness measurements were obtained near each wing model leading-edge using a surface contact profilometer. The average roughness values were recorded for the different wing leading-edge parts used throughout this research. These values range from about $0.15 \mu \mathrm{m}(6 \mu \mathrm{in}$.) for the highly-polished unpainted leading edge to approximately $1.85 \mu \mathrm{m}$ ( $73 \mu \mathrm{in}$.) for the higher-roughness, unpainted Kulite transducer leading edge. The fully-painted leading-edge part was wet sanded on both sides in a region of the leading edge within a distance of approximately 20 $\mathrm{mm}$ normal to the leading edge. The measured surface roughness in this wet-sanded region is about $0.47 \mu \mathrm{m}(18 \mu \mathrm{in}$.). 
All the different-roughness leading edge parts were tested in the tunnel. Only the fully-painted and higher-roughness unpainted leading edges were tested in flight. Because we focus here on comparisons between tunnel and flight data in this paper, only the results from these latter two leading edges are presented.

\section{B. Supersonic Wind Tunnel, Flight Vehicle, and Supporting Computations}

Due to the overview perspective of this paper, we omit detailed descriptions of both the tunnel and flight test techniques. We refer readers to a detailed description of SWT in our earlier transition research [21] on a $35^{\circ}$ sweptwing model. Similarly, more detailed information about the flight test technique can be found in previous boundarylayer transition flight research that also used the F-15B aircraft with the CLIP mounting system [23-25]. We describe below the additional model support hardware development necessary to mount our wing model on the CLIP beneath the F-15B aircraft.

Figure 6 provides some basic details about the wing model system hardware and the specific mounts used in the wind tunnel and beneath the aircraft. The wing model system mounts directly to the wind tunnel floor plate as shown in Fig. 6a. This was not the case for the flight test setup. We initially planned to mount the wing model outboard on the aircraft wing pylon to conduct the experiment in a more uniform flow field. This mounting configuration was not an option because the aircraft is only configured to acquire data from models mounted on the CLIP. Extensive experience from previous flight transition research with this mount [23-25] plus the small wing-model size combined to give us the opportunity to select a fairly uniform flow region beneath the aircraft in which to perform this experiment.

The selected wing-model position beneath the aircraft required a large adapter interface to bridge the gap between the CLIP and the wing model system (Fig. 6b). This adapter not only structurally supported the wing model, it also contained instrumentation system components (e.g., reference pressure tank, heated ESP modules, etc.). The geometry selected for the adapter was kept simple (wedge/slab) with the slab made just wide enough to seat the wing model base in a mounting pocket similar to the tunnel floor plate. We realized the adapter would affect the wing model flow field producing a significantly different one from that obtained in SWT. Some level of flow-field differences will always be present, but we can minimize them through effective design approaches.

We performed $\mathrm{M}=2$ inviscid FUN3D computations on the adapter/wing model system hanging beneath an inviscid flat plate (i.e., surrogate for bottom of aircraft) that spans the top of the computational domain. These computations provided insights into how the adapter leading-edge shocks and shoulder expansions interacted with the wing-model flow field. Various adapter geometry concepts were modeled and the one giving the best wing-model pressures matching those for the tunnel mount was determined. These computations were key to helping us match the wingmodel pressure gradients on the first $20-30 \%$ of wing chord, an important aspect in obtaining a comparable sweptwing crossflow field in both test environments. This improved adapter configuration added a splitter plate between the adapter and the wing model to shield the wing-model flow field from the adapter flow features. We also learned that by sweeping the splitter plate leading edges two vortices were created (see left middle image of Fig. 1) that prevented the splitter plate centerline boundary-layer flow from separating ahead of the wing model. Static pressure orifices were located on the splitter plate centerline to provide a way to calculate the local Mach number just ahead of the wing model. This new adapter configuration (Fig. 6b) was designed and found acceptable after a thorough structural analysis.

\section{Results}

\section{A. Baseline Swept-Wing Model Comparisons (CFD/Tunnel/Flight)}

Wing-model pressure distributions obtained from mean-flow computations and experiments are presented in Fig.7. Our crossflow transition research constraint required us to match the pressure gradient over the first $20-30 \%$ of the wing chord for both the flight and tunnel experiments. Computations were key to understanding the difference between each model mounting approach as discussed in the previous section. The insights provided from the computations allowed us to meet our pressure gradient objective. Data from all nine flights are shown to demonstrate one aspect of the level of repeatability achieved during the flight testing spanning a time frame of about a year. Similar levels of repeatability were found in the tunnel data excepting the pressures located at $x / c>0.55$ where the predicted trailingedge flow separation (due to the unsteady reflected shock/boundary-layer interaction) caused greater pressure level variations. All tunnel data are plotted in one symbol grouping (open circle) so all flight data can be displayed individually. Both the tunnel and the flight data follow the predicted pressure distribution trends providing confidence that the baseline mean flows are similar to those computed flow results.

A typical example of the model temperature distributions obtained during the tunnel and flight tests are presented in Fig. 8. These data show the wing model temperature distributions have a cold-wall boundary condition for both 
tunnel and flight though this effect is much less in the tunnel environment. The viscous computations modeled adiabatic wall boundary conditions and are close to the tunnel model temperatures. The model temperatures in the flight test are generally colder because of the cold-soaking of the wing model at altitude for an extended period of time before making a supersonic run. There was a temperature difference between the left and right sides (pilot pointof-view) of the wing model downstream of the model part line $(x / c>0.25)$. The right side of the main wing body is a one-piece construction while the left side has a smaller part (less thermal inertia) that can be removed to allow access to the installed pressure and temperature instrumentation locations (see Fig. 6b). This smaller part with less thermal inertia will warm up more rapidly under the influence of hotter conditions associated with supersonic flows. The right side of the model is where the transition front flow visualization images were captured in both the tunnel and flight experiments. In general, the laminar flow extents observed in flight with the IR technique were larger than those observed in the tunnel using a sublimation chemical technique for the same Reynolds number conditions. Although questions remain about how these different flow-visualization test techniques compare, the difference in the cold-wall boundary conditions may be a contributing factor to the longer laminar flow extents observed in flight for a given Reynolds number condition. However, it is important to note that crossflow dominated transition is considered to be less sensitive to temperature effects than first-mode dominated transition.

\section{B. Swept-Wing Flow Control Discovery in Tunnel}

Before attempting the application of DRE patterns in our tunnel testing, we studied the subsonic applications of Prof. Saric and his colleagues [5-15]. These reported experiences helped reduce the number of DRE pattern variables to be explored in our supersonic wind tunnel study. Our flow control exploration proved fruitless initially until we realized the need to perform an expanded DRE height study to see if any flow control effect could be found. We explored a number of various DRE patterns before getting any hint of what height might be effective.

To create our DRE patterns, we acquired dry rub-on appliques similar to those used by Saric and his colleagues in their earlier tunnel work. We learned manufacturers of these appliques could produce patterns with accurately spaced circular dots. The nominal height of each circular dot ranged from $12 \mu \mathrm{m}$ for a single black ink pass to $18 \mu \mathrm{m}$ for a single yellow ink pass during the manufacturing process. The addition of pigment to the ink layer increases the nominal dot height. We also learned from these applique manufacturers that dots could be formed using a double yellow ink pass during the manufacturing process and the nominal height of these dots increased to $25 \mu \mathrm{m}$. DRE patterns were developed using the different manufacturing process tweaks to get various dot heights to use as basic element building blocks.

We explored DRE patterns with heights ranging from $12 \mu \mathrm{m}$ to $25 \mu \mathrm{m}\left(\mathrm{h} / \delta_{\mathrm{DRE}} \approx 0.05-0.10\right.$ where $\delta$ DRE is the computed boundary-layer thickness at a DRE location as shown in Fig. 3) during the tunnel tests with no signs of any control effect like that observed in Saric's subsonic research. So, thinking supersonic flows might just be different, we began to develop patterns with increasing dot heights by tediously stacking pattern layers over short zone lengths. The stacking was approached carefully because of the risk of trapping dust fibers between each dot layer. As dot heights approached about $36 \mu \mathrm{m}$, we noticed a piece of lint was accidentally trapped under one dot in such a manner that the fiber lifted up ahead of the dot during the tunnel run. This observation suggested increasing DRE dot heights more might produce stronger stationary crossflow disturbances to achieve the desired control effect. This seemed counterintuitive to us because with the addition of each layer the probability that we would trip the boundary-layer flow increased steadily. Toward the end of our tunnel test, we applied a DRE pattern with two different spacings and three different heights ranging from about $100 \mu \mathrm{m}\left(\mathrm{h} / \delta_{\mathrm{DRE}} \approx 0.40\right)$ to $150 \mu \mathrm{m}\left(\mathrm{h} / \delta_{\mathrm{DRE}} \approx 0.60\right)$. This DRE pattern proved to be effective. It was designated as DRE1 and preserved for the follow-on flight test.

Figure 9 shows the flow visualization image from the sublimating chemical technique used in SWT to acquire data on the laminar flow extent. These images are shown upside down to place the model in an orientation as if it is mounted beneath the aircraft for the flight test so the flow is from right to left. The images provide an indication of the boundarylayer transition front features plus tracks of stationary crossflow vortices shed from individual roughness elements within the laminar flow region. This information provided key insights in finding a pattern (spacing, height, and diameter) to effectively control the boundary-layer transition in the wind tunnel environment for a highly-swept wing. For example, the middle set of dots with $2 \mathrm{~mm}$ spacing ( $\mathrm{s} / \lambda_{c} \approx 0.36$ ) were in the proper height range to be effective, but the closer spacing increased the neighboring element interference causing the pattern segment to be ineffective (i.e., reduced vortex tracks signs). This image also shows the laminar flow extension corresponding to each zone with the $4 \mathrm{~mm}$ spacing $\left(\mathrm{s} / \lambda_{c} \approx 0.73\right)$ in the DRE1 pattern. In this image, we see an increase in the local laminar flow length as much as $30 \mathrm{~mm}(\Delta \mathrm{x} / \mathrm{c}$ of $5 \%)$ due to the local DRE control effect.

After the tunnel test, profilometer measurements were obtained to characterize the successful DRE1 pattern geometry. These measurements are displayed in a series of plots in Fig. 10 along with arrows indicating where these 
measurements were taken. The upper plots demonstrate the difficulty with stacking individual layers to achieve a circular cylinder target shape. The bottom row of plots shows how the targeted element spacing was consistently met.

\section{Application of Flow Control Understanding to Flight Test}

After demonstrating the ability to delay transition in the tunnel, we now prepared to apply this new understanding to the flight flow-control application. Fortunately, the application was on the same wing model but this model was now going to be tested in another environment: flight. Since we were not planning to do additional boundary-layer stability analyses in advance at every possible point in the flight envelope, we developed a strategy enabling us to predict the DRE pattern spacing for other conditions between the two boundary-layer stability analyses. We created a DRE spacing design map providing trends of effective DRE spacings vs. unit Reynolds number (Fig. 11). The blackfilled circle symbols plotted came from those two stability analyses performed at Reynolds number conditions related to the tunnel testing. The predicted critical spacing trend was presumed inversely proportional to the Reynolds number (characteristic of boundary-layer phenomena) and forced to go through one of the analysis points. As expected, this trend also passed through the second analysis point. This fitted trend provided an easy way to characterize the DRE spacing between the two analysis points without having to perform additional stability analyses. The other trend of interest, subcritical spacing, is calculated as $2 / 3$ of the critical trend as suggested in previous subsonic research by Saric et al.

Even though we have a design map to predict the proper pattern spacing, three additional pieces of information are needed to make an effective DRE pattern (element height, diameter, and placement). Placement is assumed to be near the predicted neutral point (Branch I) for the most-amplified stationary crossflow critical wavelength. Height and diameter control the amplitude of the crossflow disturbance input and increasing either creates larger disturbance inputs, but there are limits for each. The element height cannot be made too tall relative to the local boundary-layer height or the elements will transition the boundary layer prematurely. Similarly, the element diameter has a limit too. If the diameter increases too much relative to the spacing, then the elements become less effective at delaying transition as each begins to interfere with its neighbor (recall tunnel data middle pattern of Fig. 9). We will expand more on this diameter effect later in the Discussion section.

We include other information on our DRE spacing design map to compare our tunnel and flight flow control experiences. Two green stars are located at a spacing of $4 \mathrm{~mm}\left(\mathrm{~s} / \lambda_{c} \approx 0.73\right)$ between unit Re of 6 and $7 \mathrm{million} / \mathrm{m}$. These represent the two tunnel conditions (Fig. 9 shows one) where pattern DRE1 was effective at promoting boundarylayer transition delay. Unfortunately, the pressure suit requirement at a similar flight test condition prevented us from getting a directly comparable test point in flight. Our test team decided to proceed with DRE1 configuration as tested in the tunnel and get our first flight data at a higher unit Reynolds number condition. The red stars on the map represent the result of that flight where the DREs tripped the boundary-layer, providing the undesired control effect. Although the two spacings in the DRE1 pattern align with the critical and half-critical spacing trends for that flight condition (Flt\#1, unit $\mathrm{Re}=8.5 \mathrm{million} / \mathrm{m}$ ), we presume the DRE1 pattern tripped the flow primarily because the element heights that delayed transition in the tunnel were too tall to work in flight at the higher Reynolds number condition. This suggested to us that another height study was necessary. From our spacing design map, we chose to do this flight DRE height study at target spacings of $2.7 \mathrm{~mm}\left(\mathrm{~s} / \lambda_{c} \approx 0.67\right)$ and $3 \mathrm{~mm}\left(\mathrm{~s} / \lambda_{c} \approx 0.75\right)$. Two DRE patterns were developed for the remainder of the flight test. The height study pattern (DRE2) details are shown in Fig. 12a. The final pattern (DRE3) tested on the unpainted wing leading edge is shown in Fig.12b.

These DRE patterns were tested in flight and IR flow visualization video data acquired to determine if we could detect any control effect. Unlike the tunnel flow visualization image data, the IR camera video images obtained in flight did not have the capability to zoom in on the leading-edge region to get detailed features of the transition front (Fig. 9). Fortunately, image frames captured from the flight IR videos show just enough of the transition front features to suggest the possibility that the desired control effect is present. Figure 13 shows an example of flow visualization images from the IR thermography technique used in flight to acquire data on the laminar flow extent for unit $\operatorname{Re}=8.5$ million $/ \mathrm{m}$. On the left side of the figure, the upper two images show the transition fronts associated with the baseline (no DRE) and flow control pattern (DRE2) configurations. In each of these images, the cold-soaked wing model is being heated by the warmer supersonic flow as the aircraft accelerates. The portion of the wing model leading-edge surface under a laminar boundary layer remains cooler (darker) than those areas under a transitional/turbulent boundary layer where the heat transfer rates are higher producing warmer areas (lighter).

The IR images show some basic features of the boundary-layer transition front. A direct comparison of these two images is shown in the processed (bottom) image. This processed image is a direct overlay of the two IR images displayed above it. The overlay technique highlights the difference in temperature levels between the two images through artificial coloring. By focusing along the transition front, the overlay will show that portion of the image as cyan if the DRE2 image has a longer laminar flow extent than the baseline. If the baseline image has a longer laminar 
flow extent, then the color in that region of the processed image is red. A plot of the DRE Spacing Map is shown to the right of the images in Figs. 13-15. Two different DRE spacings were used in the DRE2 pattern. The plotted yellow stars mark the map location corresponding to the flight condition for these images. The subsonic flow literature suggests DRE spacings near a subcritical wavelength (blue solid line) are needed to promote laminar flow. DRE zones one through four are marked in the overlay image to indicate the potential influence of the DREs on the local transition front. Zones five and six are too close to the wing tip to provide any indication of delayed transition. The only observation we can make for zones five and six is the DREs in this region did not trip the boundary layer. In the overlay image, two blue arrows point to the local transition front where effective DRE control extends the local laminar flow $25-30 \mathrm{~mm}(\Delta \mathrm{x} / \mathrm{c}$ of $4 \%-5 \%)$ beyond that of the baseline configuration. This amount of transition delay is comparable to the control effect observed in the tunnel (Fig. 9) for the DRE1 pattern. However, the element height for these two zones is nominally $25 \mu \mathrm{m}\left(\mathrm{h} / \delta_{\text {DRE }} \approx 0.10\right)$ compared to the $100-150 \mu \mathrm{m}\left(\mathrm{h} / \delta_{\text {DRE }} \approx 0.4-0.6\right)$ used for the DRE1 pattern in the tunnel. This height difference may be due to potentially higher turbulence intensity levels in the tunnel requiring greater SCF disturbance inputs to achieve the same level of DRE control effect. There does not appear to be any control effect (delay or trip) in zones three and four at this flight condition with $\mathrm{h} / \delta_{\mathrm{DRE}} \approx 0.3$.

Figure 14 shows the control effect of the DRE2 pattern at a higher Reynolds number flight condition, unit $\mathrm{Re}=$ $10.8 \mathrm{million} / \mathrm{m}$. Zones two $\left(\mathrm{h} / \delta_{\mathrm{DRE}} \approx 0.10\right)$ and four $\left(\mathrm{h} / \delta_{\mathrm{DRE}} \approx 0.30\right)$ show transition delays similar to unit $\mathrm{Re}=8.5$ million $/ \mathrm{m}$. It is interesting to note the transition delay above zone one. This delay in transition is not due to any DRE control effect. Although some suggest this may result from a temperature effect (i.e., freestream static temperature for the DRE2 configuration is $9 \mathrm{~K}$ cooler than the baseline), it is not yet clear what actually causes this uncontrolled transition delay to occur in this area. We believe this level of temperature difference between the baseline and control configurations is not sufficient to cause this transition front difference. The next set of IR images of Fig. 15 support this belief by presenting a comparison with a temperature difference of similar magnitude but with the opposite sign.

Figure 15 presents the control effect of the DRE3 pattern on the unpainted wing leading edge at a flight unit $\mathrm{Re}=$ $7.4 \mathrm{million} / \mathrm{m}$. The control effect shown for the unpainted wing leading edge configuration has a freestream static temperature difference with the DRE3 configuration $8 \mathrm{~K}$ warmer than the baseline. Even with the DRE3 configuration exposed to a warmer freestream condition, a similar DRE control effect appears. This DRE3 pattern consisted of a single zone of DREs that span most of the wing leading edge. Because this pattern is consistent, we expected to see laminar flow regions extended over more of the wing model span. The overlay image shown in Fig. 15 has a consistent band of cyan along the transition front as expected. Note we changed the wing leading-edge part to the unpainted leading-edge configuration with a completely new DRE pattern application and still achieved a transition delay effect comparable to earlier flight configurations. The elements of this new pattern are the shortest used in the flight test, nominally $18 \mu \mathrm{m}$ tall $\left(\mathrm{h} / \delta_{\mathrm{DRE}} \approx 0.07\right)$.

\section{Discussion}

\section{A. Insights Gained from Observed DRE Control Effect}

We learned a lot from the experiences of applying crossflow control on the same wing model in these two test environments. Overall, the control effect shown both in the tunnel and flight are of similar size. It is also useful to compare our results with some of the earlier subsonic research efforts to get a better understanding of what makes DRE patterns more effective. Figure 16 graphically shows a series of DRE patterns studied and all are drawn at the same relative scale in this figure. Two red U-shaped lines are placed around neighboring elements for each pattern to represent notional horseshoe vortex shedding as the flow moves from left-to-right. Beneath each pattern shown are parameters (Reynolds number, leading-edge sweep, stationary crossflow wavelength parallel to leading edge, spanwise wavelength, element diameter, element height, and spanwise wavelength-to-diameter ratio) listed to characterize each element layout. In general, as Reynolds number increases wavelengths decrease. Also, as sweep increases, the spanwise wavelength decreases for a given wavelength parallel to the leading edge. During our research, we observed how important these factors are to consider because they determine how effective a DRE pattern is in a given flow control application.

The first three patterns on the left of Fig. 16 represent subsonic studies conducted by Saric et al. as they explored the flow control effect from low Reynolds number tunnel research to higher Reynolds number subsonic flight research. In the tunnel work, all DRE patterns worked as intended either to trip the flow (critical spacing) or delay transition (subcritical spacing). We calculated the spanwise wavelength-to-diameter ratio used in this work to be 2.8 as noted. Since these patterns worked as intended, this ratio value is shown in green. For the higher Reynolds number subsonic flight work, this ratio dropped to 2.0 with the chosen element diameter. This is shown in orange to represent the reported inconsistent effectiveness of this DRE pattern [13,15]. This observation suggests pattern elements need 
enough distance between neighboring elements so each can function as an isolated roughness element and generate sufficient crossflow disturbances without significant interference (i.e., element crowding effect).

The next two patterns show the NASA supersonic crossflow research on a $35^{\circ}$ swept-wing model in SWT [21]. The Reynolds number tested was significantly higher requiring very small pattern wavelengths and element diameters. The ratio for the critical spacing configuration worked presumably due to the spanwise wavelength-to-diameter ratio being similar to Saric's early tunnel research. We were somewhat confused about why the subcritical spacing pattern did not work in this research. However, based on our recent swept-wing research (last three patterns shown in Fig. 16), a potential reason why this pattern was ineffective may be related to this key ratio for the DRE pattern being too low (value of 1.7 shown in red). Element height may also be a factor here considering how unexpectedly tall the elements needed to be in our SWT $65^{\circ}$ swept-wing model research (i.e., $145 \mu \mathrm{m}$ in tunnel compared to $18 \mu \mathrm{m}$ in flight).

Of the last three patterns shown, the two at unit $\mathrm{Re}=6.2 \mathrm{million} / \mathrm{m}$ represent the successful flow control demonstration in SWT. As shown in Fig. 9, the two $4 \mathrm{~mm}$ zones locally delayed transition while the middle zone with $2 \mathrm{~mm}$ spacing did not change the transition front from the baseline. The $2 \mathrm{~mm}$ pattern had a spanwise wavelength-todiameter ratio value of 1.9 , which is consistent with values of other patterns that did not work or did not work consistently. From these observations we conclude that beyond establishing the appropriate subcritical wavelength it is just as important to make sure the spanwise wavelength-to-diameter ratio is 2.7 or higher based on available data. If this ratio for a given DRE pattern is below 2.7 (gray area between $2.0-2.7$ ), then pattern elements may become too crowded and the pattern will probably be ineffective due to neighboring element interference. When considering a robust DRE pattern design, this ratio may need to be made larger to stay away from this gray area and remain effective at off-design conditions.

\section{B. DRE Control Effect Potential}

We now see DRE control effects exist in both tunnel and flight test environments for carefully designed DRE patterns. Stepping back from this focused view of DRE patterns, we look more broadly at how these observed DRE control effects fit into a bigger laminar flow control picture. We do this because at the flow control application level $30 \mathrm{~mm}(\Delta \mathrm{x} / \mathrm{c}$ of $5 \%)$ of increased laminar flow extent is not impressive and certainly will not meet the drag reduction requirement supersonic transports need to become practical. Let us first consider how this control effect varies by looking at changes in the transition Reynolds number with wing leading-edge sweep (Fig. 17).

The NASA $65^{\circ}$ swept-wing DRE control effect is shown in Fig. 17 for both the tunnel and flight environments. The DRE control effect is similar for the two environments even though the transition Reynolds number for the wing model in flight is about twice that in the tunnel. We speculate the flight transition Reynolds numbers are greater than those in the tunnel because of the significant difference in the cold-wall boundary condition that exists in the flight test environment (Fig. 8).

The ASU $45^{\circ}$ swept-wing, DRE control tunnel demonstration was the original discovery of this flow control concept made by Saric's research team [8]. They recorded a control effect that produced a longer extension of the laminar flow region $\left(15 \mathrm{~cm}\right.$ ) with a lower sweep angle than that of the NASA $65^{\circ}$ wing model. The biggest DRE control effect $(0.3 \mathrm{~m})$ was demonstrated by Saric's team in flight research at a higher Reynolds number with a $30^{\circ}$ swept wing [12]. This research showed how an increase in wing leading-edge surface roughness (i.e., painting) can have a dramatic impact on the laminar flow extent and how the DRE control effect can restore some of the laminar flow loss. This is a really interesting case that makes us wonder if the potential of DREs may lay in a different role of protecting NLF from increases in background surface roughness.

The four DRE control effect demonstrations shown in Fig. 17 also illustrate how reducing the wing sweep (i.e., crossflow reduction) allows the DREs to have a larger control effect. Although the sections of each of these wing models is considered in some sense an NLF design, they really are not when considering an overall wing design. The wing sections used in our DRE studies generally give the DREs a really challenging control problem because of the strong favorable pressure gradients designed into the wing sections. So, it is not surprising that the observed DRE control effects are not dramatic. The question is how would a practical NLF swept-wing be designed and how could a DRE flow control application enhance that design. Results from JAXA's supersonic NLF wing design research (shown in Fig. 17) reflect an attempt to provide such a supersonic NLF wing design.

The JAXA research did not perform any DRE studies but instead focused on developing an NLF wing design method for supersonic aircraft. This design method modified the leading-edge pressure distribution for a highly-swept wing to minimize the crossflow [27]. In this research, Yoshida notes that the laminar flow extent increase in flight at the design lift coefficient with decreasing Reynolds number did not occur as expected. His team speculates the cause may be related to a higher leading-edge surface roughness $(1 \mu \mathrm{m})$ from the manufacturing process than the intended design level of $0.3 \mu \mathrm{m}$. This experience serves as a reminder that current NLF wing designs do not directly model the 
effect of background surface roughness on the predicted laminar flow extent. We can imagine the potential impact that an effective DRE pattern might have in this situation if the DREs act in a role of protecting the NLF from the increased background surface roughness.

Finally, a bigger picture of NLF and LFC (Laminar Flow Control) may look like that shown in Fig. 18. Examples of active LFC demonstrations such as the X-21A [2] and the F-16XL-2 [4] give some sense of the potential laminar limits in flight. The F-14A subsonic wing [28] and the NEXST-1 supersonic wing [27] demonstrations also give a sense of where we are with NLF wing designs. New NLF swept-wing design approaches are being developed to promote laminar flow through the minimization of inherent crossflows. In this bigger laminar flow landscape, the DRE flow control approach alone will not be sufficient to promote large enough laminar flow regions for practical wing designs. Further DRE geometry refinements may create some small additional control effects, but the major potential may lay in maximizing the synergy between the DREs and an improved crossflow NLF wing design approach. These improved crossflow attenuated NLF design approaches [29-34] for swept wings may provide a good opportunity to explore this potential.

\section{Conclusion}

The swept-wing, laminar flow control research presented represents the culmination of a seven-year research effort to determine if DRE flow control technology has any relevance for supersonic swept-wing applications. Of course, ground-breaking research performed by Prof. Saric and his colleagues originally discovered the potential for DRE patterns to extend subsonic swept-wing laminar flow regions as the long list of included references from the past two decades attests. Our supersonic research built upon this foundation and adds to the knowledge of how to design more effective DRE flow control patterns. To do this, we needed support from computations, wind tunnel, and flight studies. A balanced approach leverages the strengths and weaknesses of each of these study areas to get the most from this type of research effort.

One of our research's main contributions to the knowledge of how to design more effective DRE flow control patterns includes establishing that the flow control effect indeed exists in both the supersonic wind tunnel and flight environments. Presumably this knowledge also applies to the subsonic flight environment, though more research is needed to confirm this hypothesis. Our supersonic wind tunnel research demonstrates the importance of considering not only the DRE spacing but also the individual element diameters, specifically the ratio of spanwise spacing-todiameter.

Another contribution of our research showed the close connection between carefully designed and executed wind tunnel and flight tests, both of which benefit greatly from supporting computational studies. These research techniques will always differ at some level, but proper engineering team judgment minimizes these differences to adequately address the flow control research question. A good example from our study includes dealing with different flow disturbance levels in the wind tunnel and in flight. Although conditions such as Mach number and unit Reynolds number were matched in both environments, we still needed to adjust the DRE pattern height in the tunnel to be taller (while still not tripping the boundary layer) than that in flight to observe similar control effects. We attempted this counter-intuitive height adjustment because we understood some of the character of the competing crossflow transition mechanisms and paid close attention to the wind tunnel observations during the exploration of the DRE design space. It would be easy to dismiss the wind tunnel results with the higher flow-disturbance levels, but the opportunity to gain key insights into how to design effective DRE flow-control patterns would be missed. Exploring the extremely large DRE pattern design space in flight studies alone to find effective patterns is inherently cost prohibitive. In the final analysis, both wind tunnel and flight studies are necessary for effective flow-control technology development along with the support of effective computational studies.

The final contribution our research offers is somewhat subtler. It involves potentially shifting one's mindset from thinking of DRE patterns in the flow control role of extending laminar flow regions to a different role of protecting already established laminar flow regions from the negative effects of increased background random surface roughness along the wing leading edge. This distinction is important for two reasons. First, the observed DRE flow control effects observed are relatively small as demonstrated in the current and previous DRE research studies. All these studies assumed some level of swept-wing crossflow pressure gradient, which may in fact be too extreme as applied in this study. In essence, we have given this flow control technology a too difficult challenge to surmount. Secondly, new developments in crossflow attenuated NLF wing design techniques to passively reduce swept-wing crossflow levels are emerging in the laminar flow research [29-34].

These improved NLF wing design methods could potentially offer wing designers lower drag options for higher speed aircraft. A key point to remember about current NLF design techniques is that they do not yet model the effects of wing leading-edge surface roughness. In practice, wing leading edges will have some level of random background 
surface roughness (insect contamination, paint, handling, wear, etc.). Maintaining a pristine surface is not practical in typical aircraft operations. So, if we learn how to effectively integrate DRE patterns into these new NLF wing designs, then DREs may potentially protect these passively created laminar flow regions from those operational environmental factors.

If these improved NLF wing design methods are successful, then questions remain about how to effectively integrate the resulting wing designs and an effective DRE pattern. One such question is where on the wing leading edge to locate the DRE patterns given the aggressive flow acceleration on the wing leading edge inherent with these wing designs. Another is whether the DRE pattern can remain passive (preferred) or does it need to be active to handle changing flight conditions (e.g., angle of attack, Reynolds number/altitude, etc.) throughout the supersonic cruise trajectory. Follow-on research is needed, but the potential impact of a successful LFC system on an operational aircraft would truly be a game changer.

\section{Acknowledgments}

This work was performed as part of the Commercial Supersonic Technology (CST) Project within the NASA Fundamental Aeronautics Program. The CST Project Manager, Peter Coen, and his leadership team are thanked for their continued sponsorship throughout the long-term research effort. Any research effort of this magnitude requires a large team whose many members make significant contributions. The authors wish to thank members of the LaRC and the AFRC team for sharing their expertise and insights throughout this research effort: Jenna Eppink, Frank Chen, Mike Frederick, Michelle Haupt, Tom Hulgan, Ashante Jordan, Mike Kegerise, Catherine McGinley, Brett Pauer, Natalie Spivey, Brian Strovers, and Steve Wilkinson. Jared Fell is recognized for designing the wing model system and support hardware necessary to attach the model to the aircraft. Mark Roth, Tom Hall, and Wayne Geouge are recognized for their craftsmanship and attention to detail that produced the high-quality installation of the model instrumentation. The robust model paint work resulted from thorough research and painting skills practiced by Chris McClain. The authors thank the SWT support staff for ensuring we obtained high quality tunnel data: Glen Brehm, Bob Edwards, David Gary, Kathleen Jerrils, John Warren, and Cliff Williford. We also thank Walt Kondracki, Andrea Muir, and Chris Brooke for ensuring the F-15B aircraft and wing model were ready before each test flight as well as providing valuable support during flow control model changes. Finally, the authors thank the pilots who consistently pushed the envelope to obtain high-quality flight data exactly at the conditions of interest: Jim Less and Nils Larson.

\section{References}

[1] Domenic, J. M., Bobbitt, P. J., Plotkin, K. J., Shepherd, K. P., Coen, P. G., and Richwine, D. M., "Sonic Boom: Six Decades of Research," NASA SP-2014-622.

[2] Joslin, R. D., "Overview of Laminar Flow Control," NASA/TP-1998-208705.

[3] Joslin, R. D., “Aircraft Laminar Flow Control," Annual Review in Fluid Mechanics, vol. 30, 1998, pp. 1-29.

[4] Anders, S. G. and Fischer M. C., "F-16XL-2 Supersonic Laminar Flow Control Flight Test Experiment," NASA TP-1999209683.

[5] Radeztsky, Jr., R. H., Reibert, M. S., Saric, W. S., and Takagi, S., "Effect of Micron-Sized Roughness on Transition in SweptWing Flows," AIAA Journal, vol. 37, no. 11, Nov. 1999.

[6] Reibert, M. S. and Saric, W. S., "Review of Swept-Wing Transition,” AIAA Paper 1997-1816.

[7] Saric, W. S., Carrillo, Jr., R. B., and Reibert, M. S., "Leading-Edge Roughness as a Transition Control Mechanism," AIAA Paper 1998-0781.

[8] Saric, W. S., Carrillo, Jr., R. B., and Reibert, M. S., "Nonlinear Stability and Transition in 3-D Boundary Layers," Meccanica, vol. 33, 1998, pp. 469-487.

[9] Haynes, T. S. and Reed, H. L., "Simulation of Swept-Wing Vortices Using Nonlinear Parabolized Stability Equations," Journal of Fluid Mechanics, vol. 405, 2000, pp. 325-349.

[10] Saric, W. S., Reed, H. L., and White, E. B., "Stability and Transition of Three-Dimensional Boundary Layers," Annual Review in Fluid Mechanics, vol. 35, 2003, pp. 413-440.

[11] Saric, W. S. and Reed, H. L., “Crossflow Instabilities-Theory \& Technology,” AIAA Paper 2003-771.

[12] Saric, W. S., Carpenter, A. L., and Reed, H. L., "Laminar Flow Control Flight Tests for Swept Wings: Strategies for LFC," AIAA Paper 2008-3834.

[13] Carpenter, A. L., Saric, W. S., and Reed, H. L., "In-Flight Receptivity Experiments on a 30-Degree Swept-Wing using MicronSized Discrete Roughness Elements," AIAA Paper 2009-590.

[14] Hunt, L. E. and Saric, W. S., "Boundary-Layer Receptivity of Three-Dimensional Roughness Arrays on a Swept-Wing," AIAA Paper 2011-3881.

[15] Saric, W. S., West, D. E., Tufts, M. W., and Reed, H. L., "Flight Test Experiments on Discrete Roughness Element Technology for Laminar Flow Control," AIAA Paper 2015-0539.

[16] Borodulin, V. I., Ivanov, A. V., Kachanov, Y. S., and Hanifi, A., “Laminar-Turbulent Delay on a Swept Wing,” International Conference on the Methods of Aerophysical Research, 2016 AIP Conf. Proc. 1770, 030065, pp. 1-12. 
[17] Schuele, C.Y., Corke, T. C., and Matlis, E., "Control of Stationary Cross-Flow Modes in a Mach 3.5 Boundary Layer Using Patterned Passive and Active Roughness," J. Fluid Mechanics, vol. 718, pp. 5-38, Feb. 2013.

[18] Saric, W. S., Reed, H. L., and Banks, D. W., "Flight Testing of Laminar Flow Control in High-Speed Boundary Layers," NATO-RTO-MP-AVT-111/RSM, 2005.

[19] Balakumar, P. and King, R. A., "Receptivity to Roughness, Acoustic, and Vortical Disturbances in Supersonic Boundary Layers Over Swept Wings,” AIAA Paper 2011-3880.

[20] Balakumar, P. and King, R. A., "Receptivity and Stability of Supersonic Swept Flows," AIAA Journal, vol. 50, Jul. 2012, pp. 1476-1489.

[21] Owens, L. R., Beeler, G. B., Balakumar, P., and McGuire, P. J., "Flow Disturbance and Surface Roughness Effects on CrossFlow Boundary-Layer Transition in Supersonic Flows," AIAA Paper 2014-2638.

[22] McGuire, P. J., "Spectral Analysis of Stationary Crossflow Vortex Tracks in Sublimating Chemical Using Image Processing," AIAA Paper 2014-3077.

[23] Banks, D. W., Frederick, M. A., Tracy, R. R., Matisheck, J. R., and Vanecek, N. D., "In-Flight Boundary-Layer Transition on a Large Flat Plate at Supersonic Speeds," 15 ${ }^{\text {th }}$ International Symposium on Flow Visualization, Minsk, Belarus, June 2012.

[24] Sturdza, P. and Rajnarayan, D., "Design and Validation of a Supersonic Natural Laminar Flow Test Article," AIAA Paper 2014-2176.

[25] Garzon, G. A., Matisheck, J. R., Banks, D. W., and Frederick, M. A., "Supersonic NLF Robustness Flight Testing: Transition Due to Discrete Roughness Elements," AIAA Paper 2014-2841.

[26] Biedron, R. T., Carlson, J.-R., Derlaga, J. M., Gnoffo, P. A., Hammond, D. P., Jones, W. T., Kleb, B., Lee-Rausch, E. M., Nielsen, E. J., Park, M. A., Rumsey, C. L., Thomas, J. L., and Wood, W. A., "FUN3D Manual: 13.2," NASA/TM-2017219661, 2017.

[27] Yoshida, K., "Supersonic Drag Reduction Technology in the Scaled Supersonic Experimental Airplane Project by JAXA," Progress in Aerospace Sciences, vol. 45, 2009, pp. 124-146.

[28] Trujillo Anderson, B. and Meyer, Jr., R. R., "Effects of Wing Sweep on In-Flight Boundary-Layer Transition for a Laminar Flow Wing at Mach Numbers From 0.6 to 0.79," NASA TM-101701, 1990.

[29] Campbell, R. L., Campbell, M. L., and Streit, T., "Progress Toward Efficient Laminar Flow Analysis and Design," AIAA Paper 2011-3527.

[30] Ueda, Y., Yoshida, K., Matsushima, K., and Ishikawa, H., "Supersonic Natural-Laminar-Flow Wing-Design Concept at HighReynolds-Number Conditions," AIAA Journal, vol. 52, 2014, pp. 1294-1306.

[31] Vermeersch, O., Yoshida, K., Ueda, Y., and Arnal, D., "Natural Laminar Flow Wing for Supersonic Conditions: Wind Tunnel Experiments, Flight Test and Stability Computations," Progress in Aerospace Sciences, vol. 79, 2015, pp. 64-91.

[32] Lynde, M. N. and Campbell, R. L., "Expanding the Natural Laminar Flow Boundary for Supersonic Transports," AIAA Paper 2016-4327.

[33] Campbell, R. L. and Lynde, M. N., "Natural Laminar Flow Design for Wings with Moderate Sweep," AIAA Paper 20164326.

[34] Ishikawa, H., Ueda, Y., and Tokugawa, N., "Natural Laminar Flow Wing Design for a Low-Boom Supersonic Aircraft,” AIAA Paper 2017-1860. 


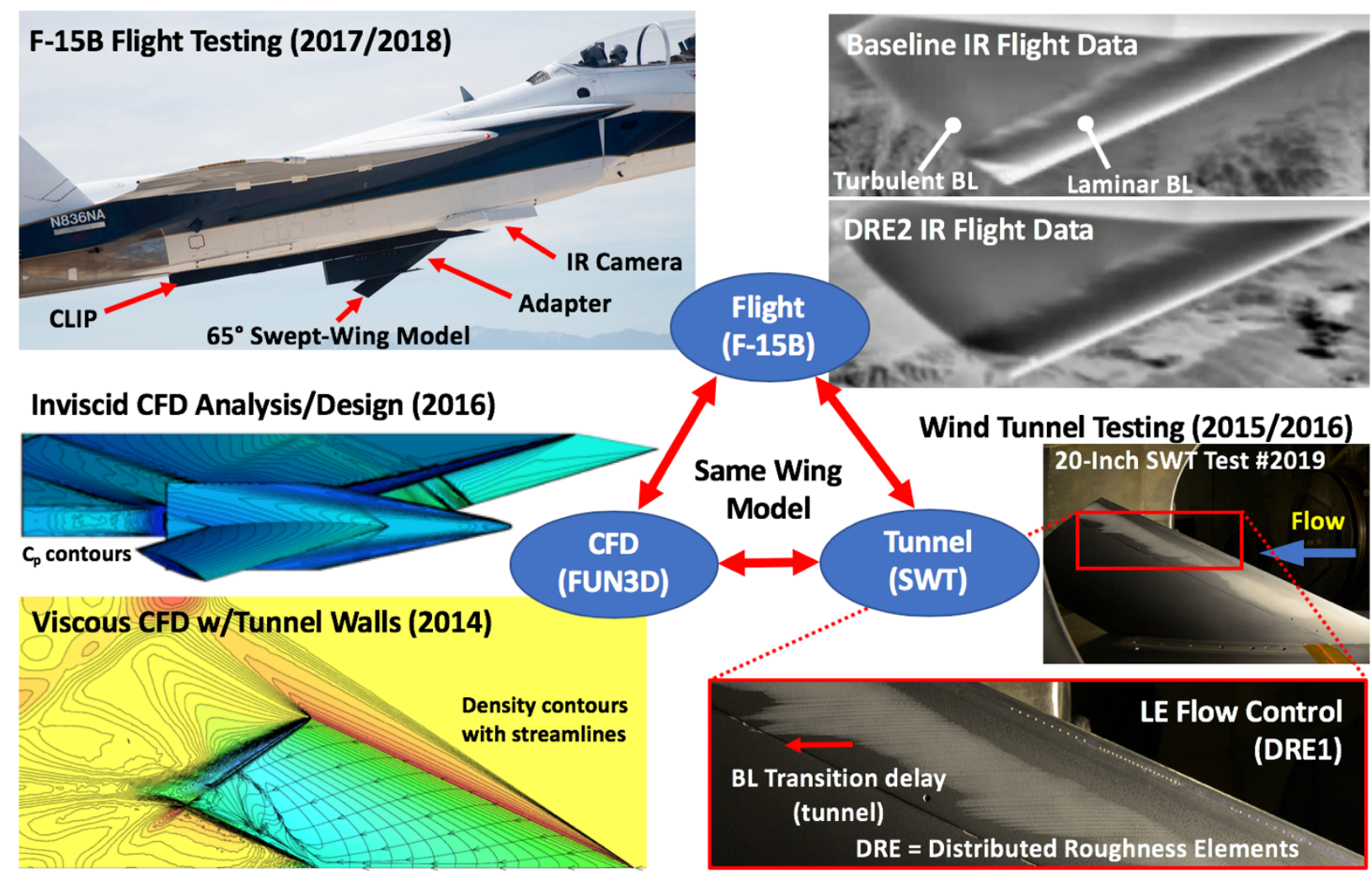

Fig. 1 NASA swept-wing laminar flow research.

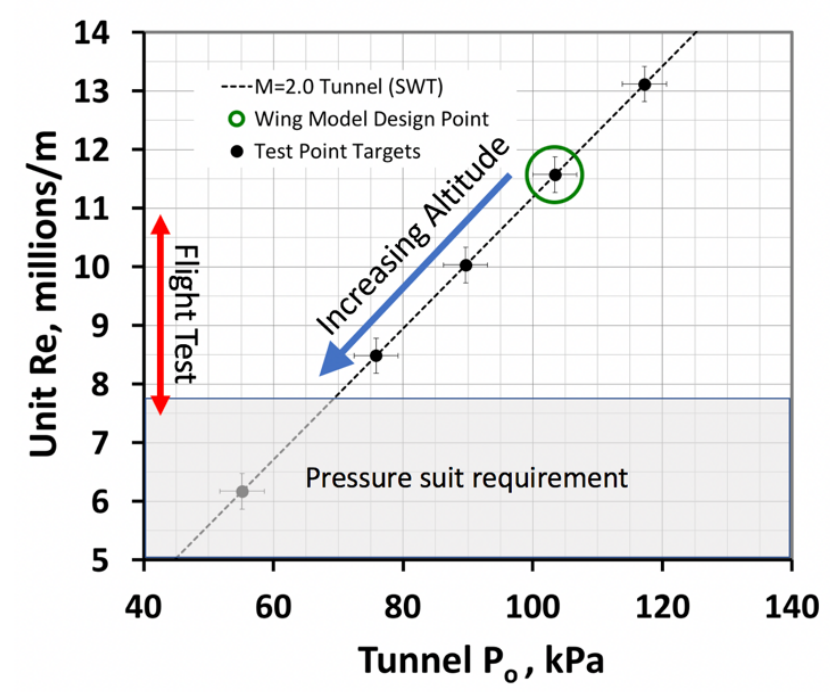

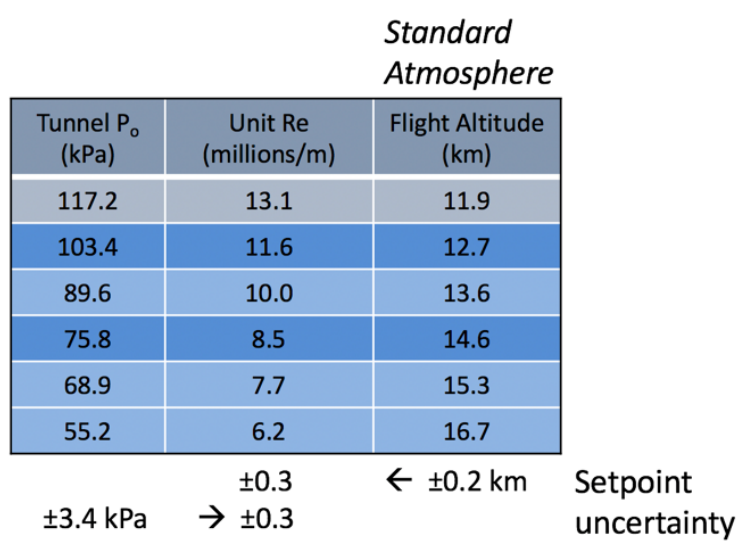

Fig. 2 Swept-wing model research test conditions. 


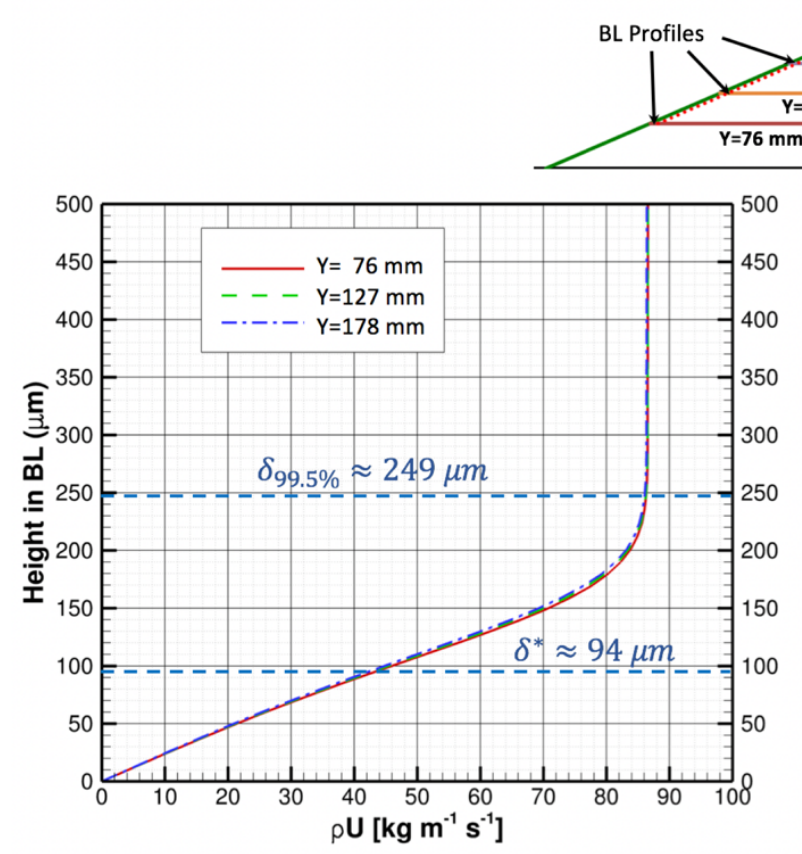

a) Mass-flux profiles.

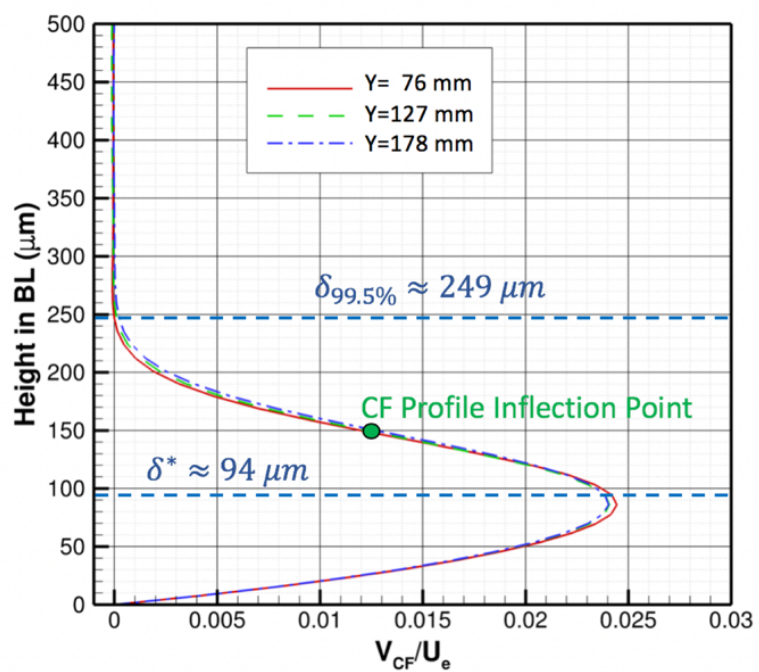

b) Crossflow velocity profiles.

Fig. 3 Predicted (FUN3D) wing model leading-edge boundary-layer character across span at $\mathbf{x} / \mathbf{c}=0.02$.

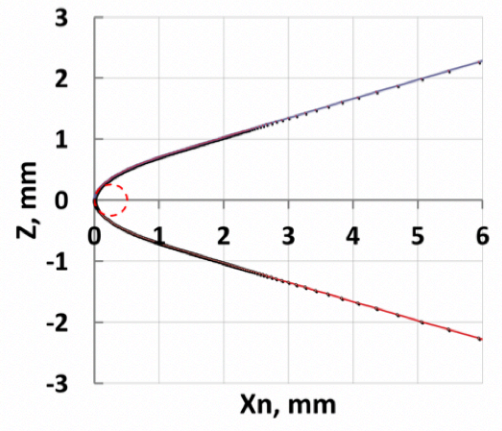

a) Close-up of leading edge.

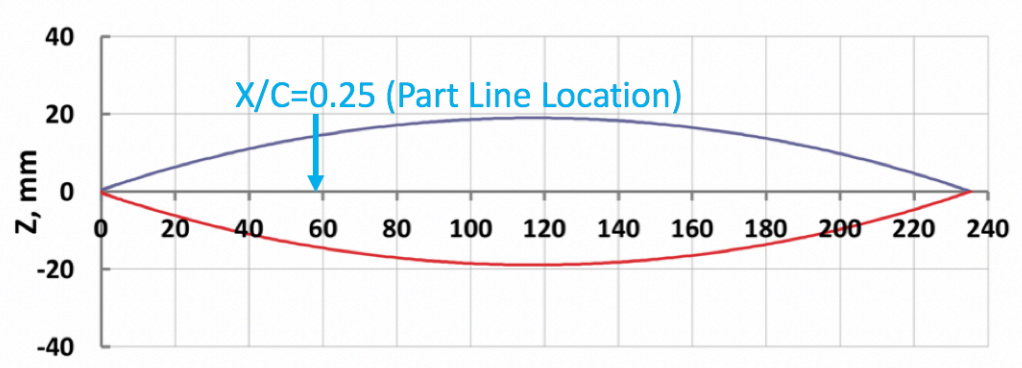

$\mathrm{Xn}, \mathrm{mm}$

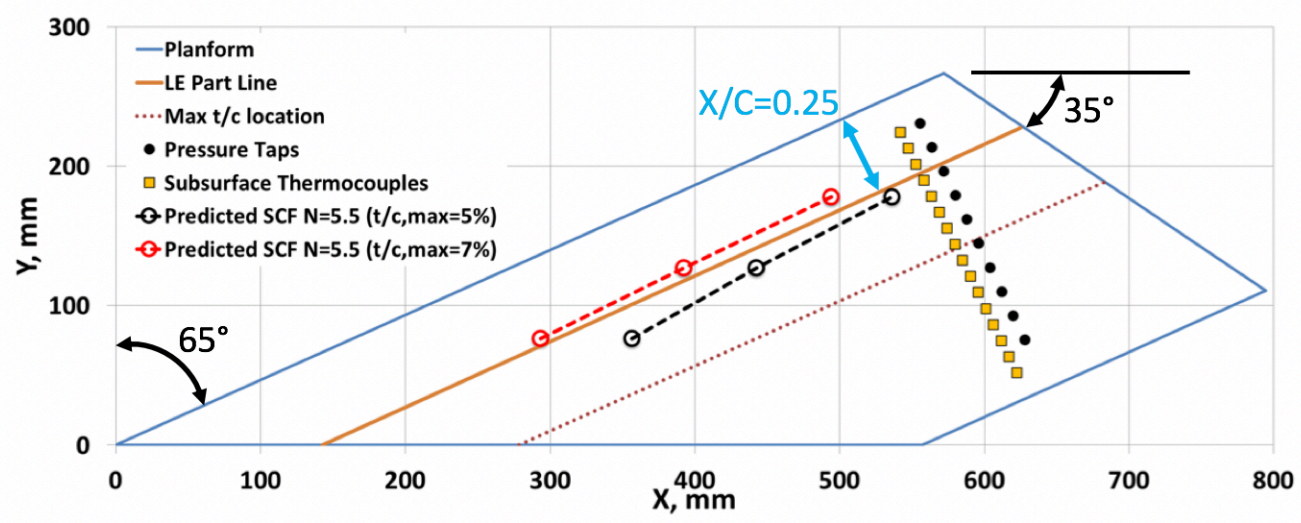

c) Wing planform with key features noted.

Fig. 4 Final wing-model design geometry. 


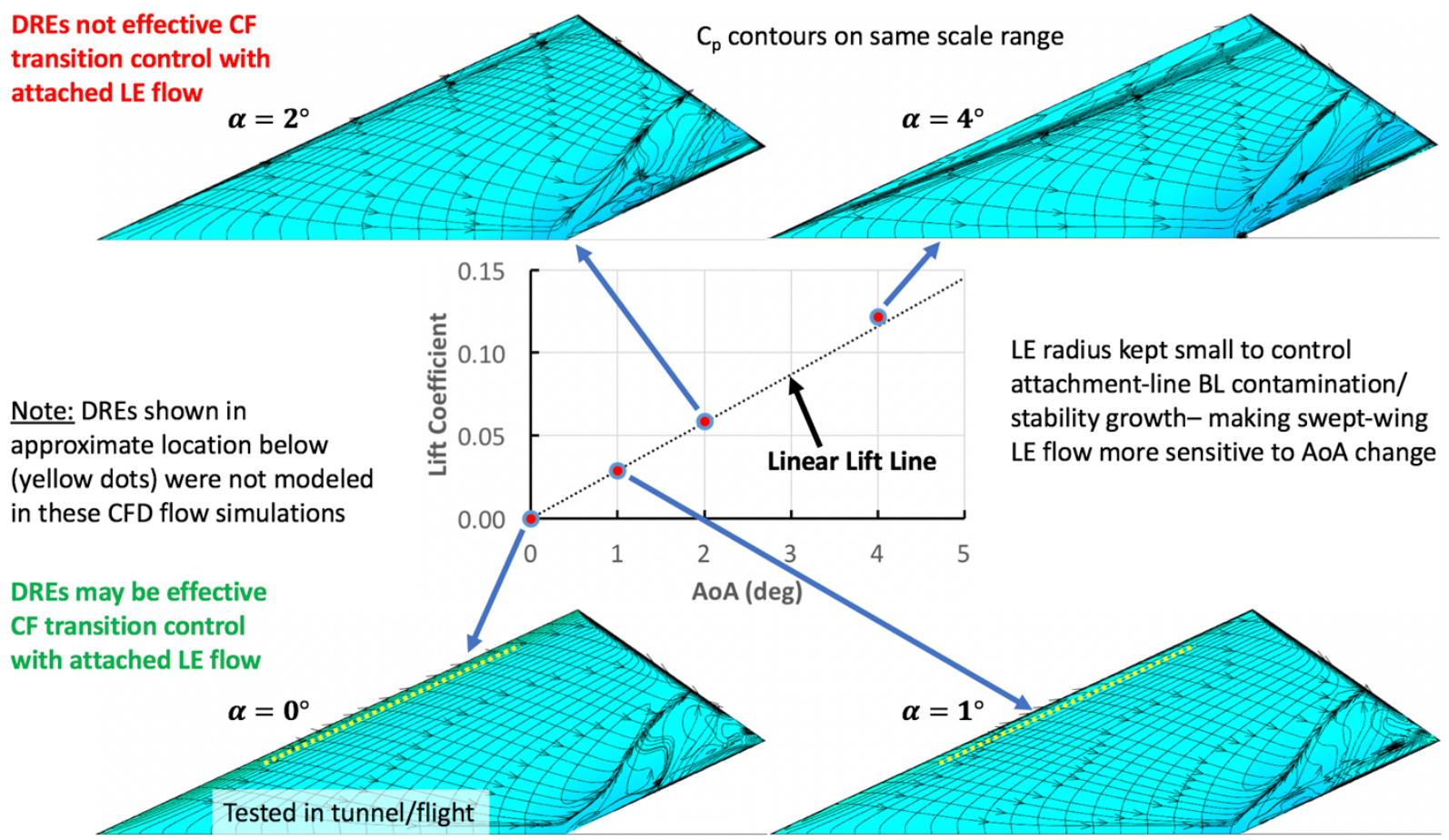

Fig. 5 Predicted (FUN3D) wing-model sensitivity to angle of attack.

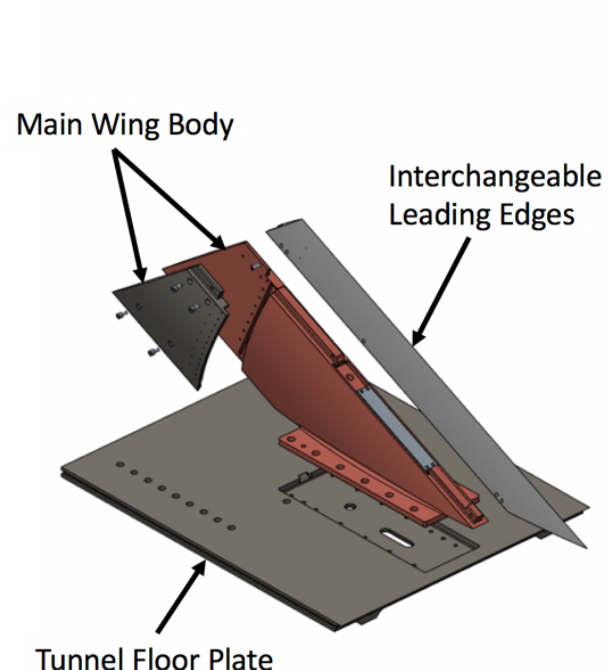

a) Exploded view of wing-model assembly on tunnel floor plate mount.

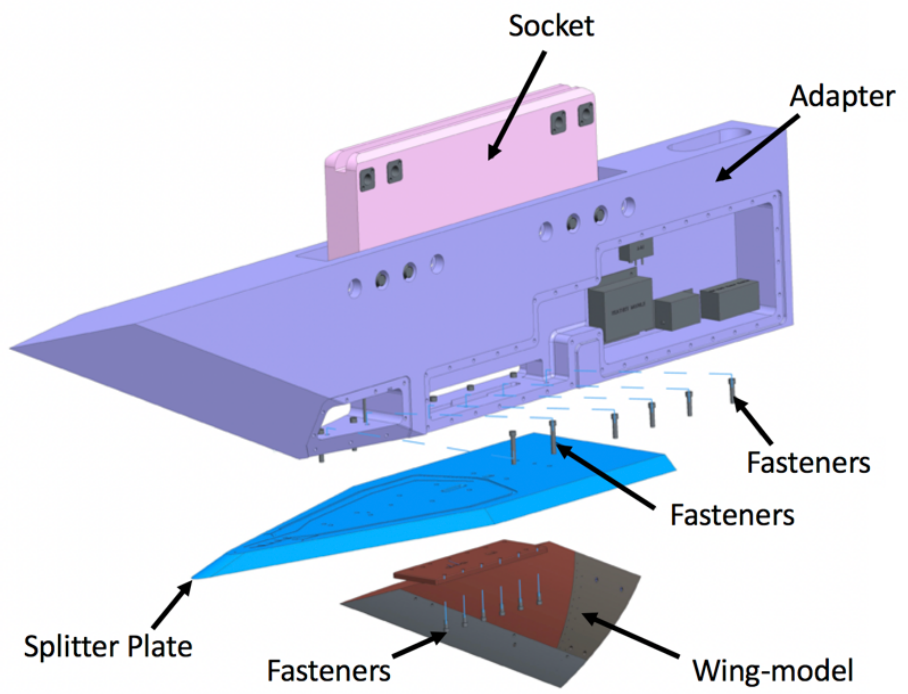

b) Wing-model assembly on splitter plate and aircraft adapter mount.

Fig. 6 Swept-wing model and support hardware design. 


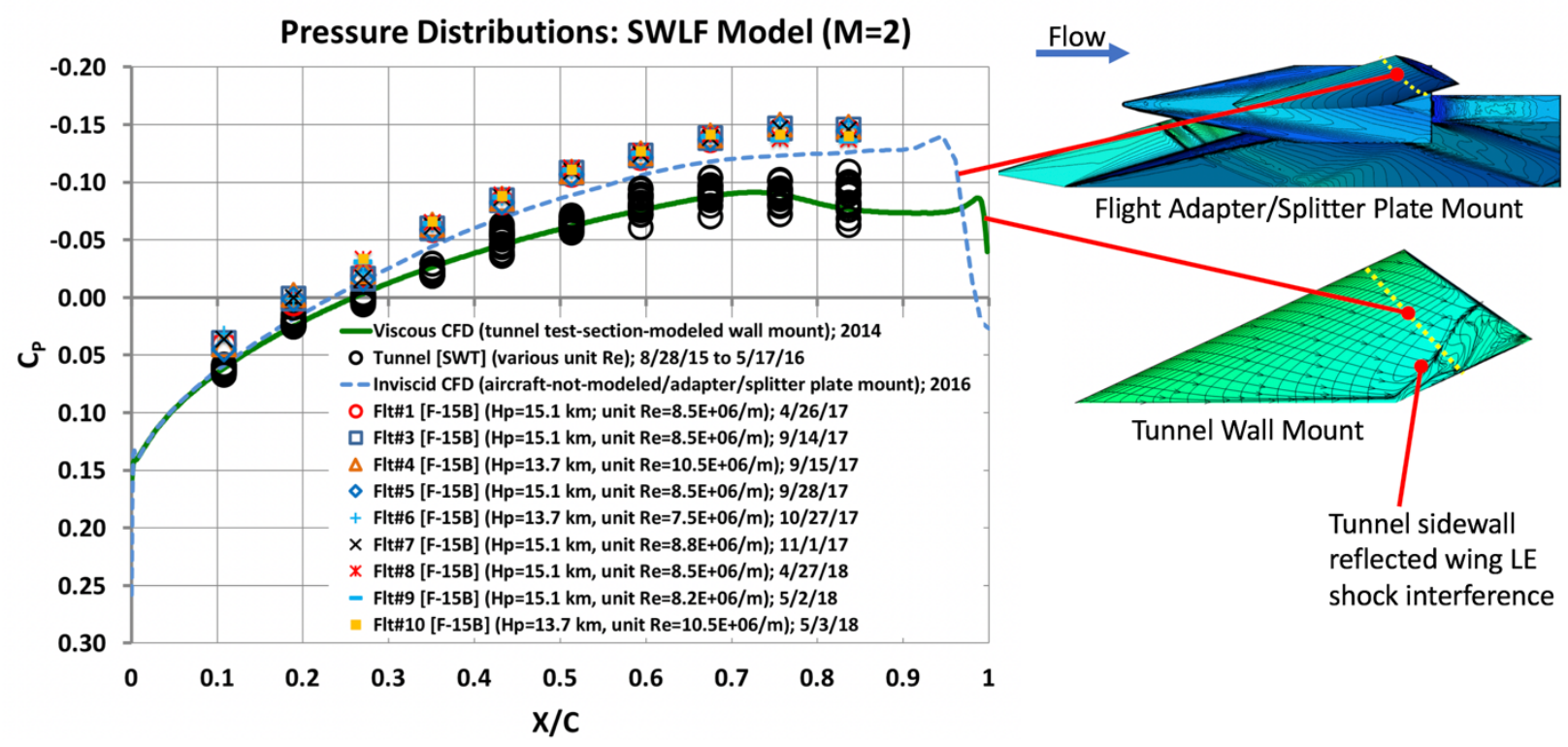

Fig. 7 Comparison of wing-model pressure distributions (M=2, CFD/Tunnel/Flight).

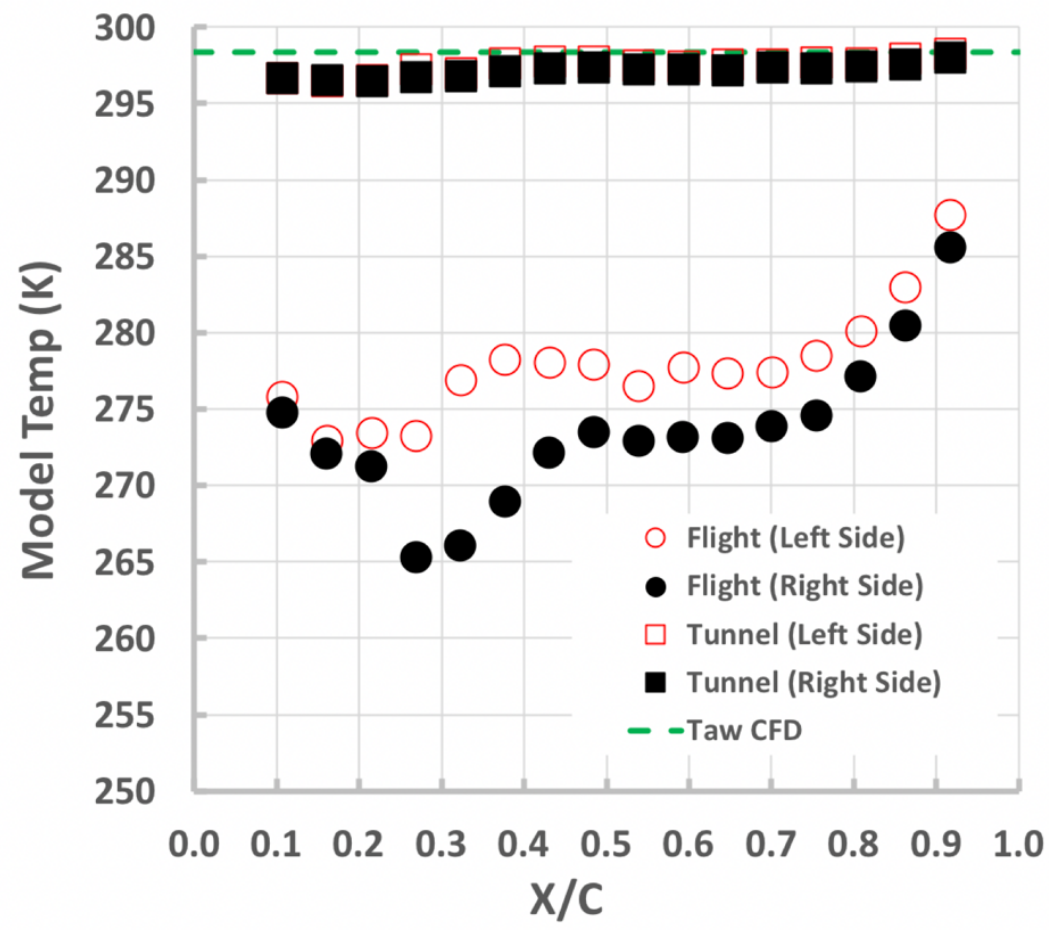

Both tunnel and flight model temperature measurements have a cold-wall boundary condition. However, the tunnel data are closer to adiabatic wall conditions.

Fig. 8 Comparison of wing-model temperature distributions (M=2, CFD/Tunnel/Flight). 


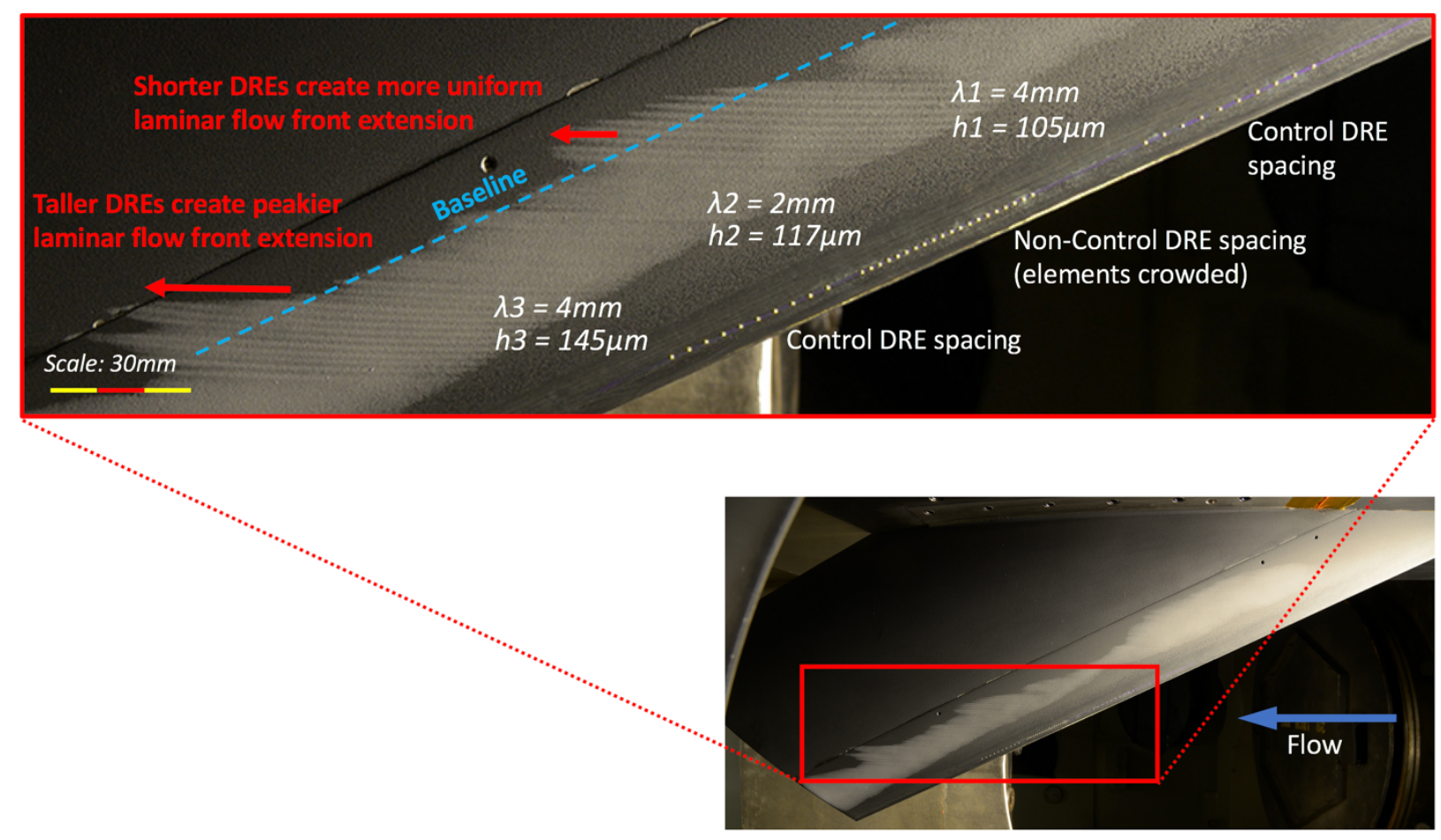

Fig. 9 Tunnel sublimation technique demonstrating DRE control effect (transition delay).

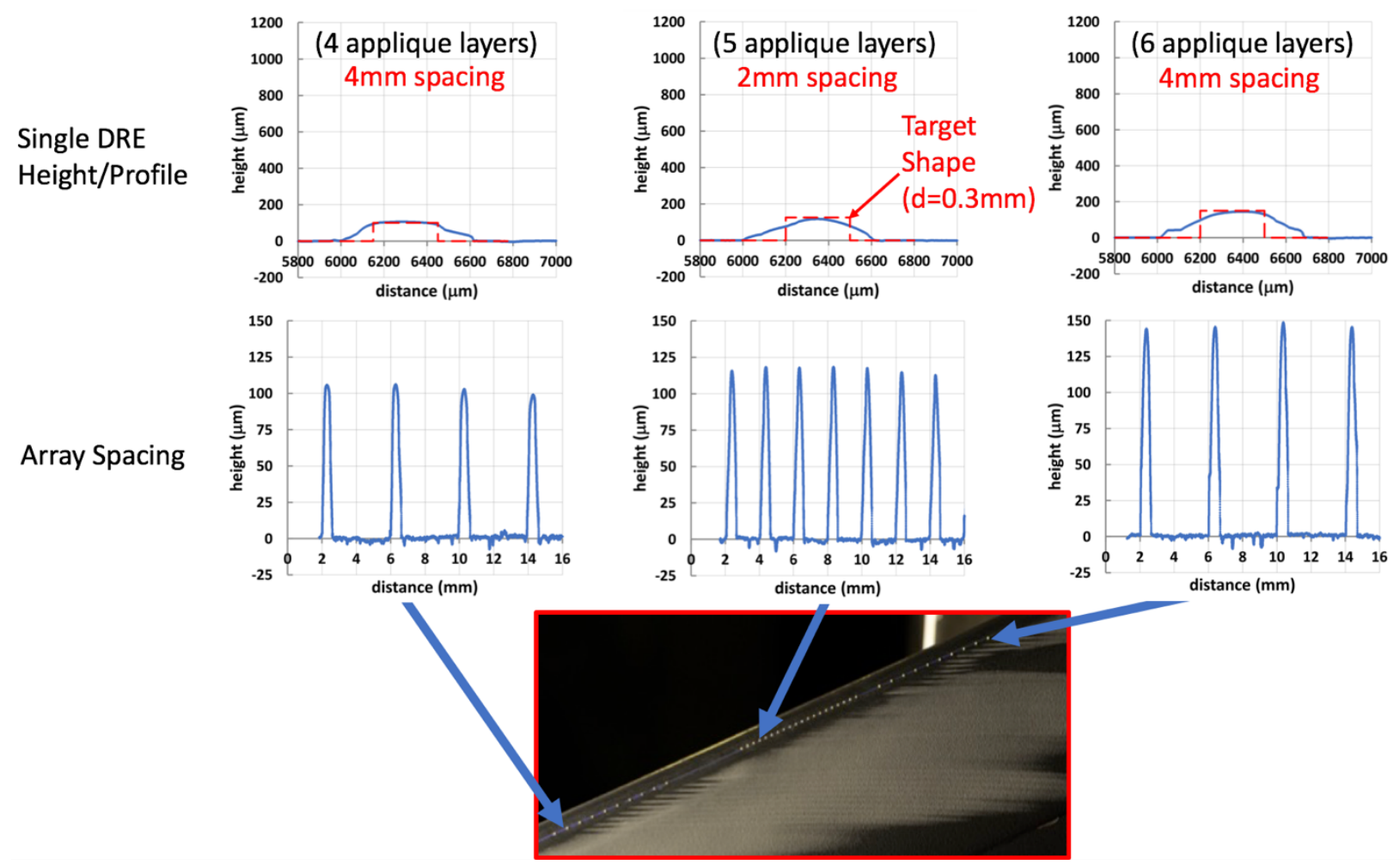

Fig. 10 Effective DRE1 pattern geometry post-test measurements. 


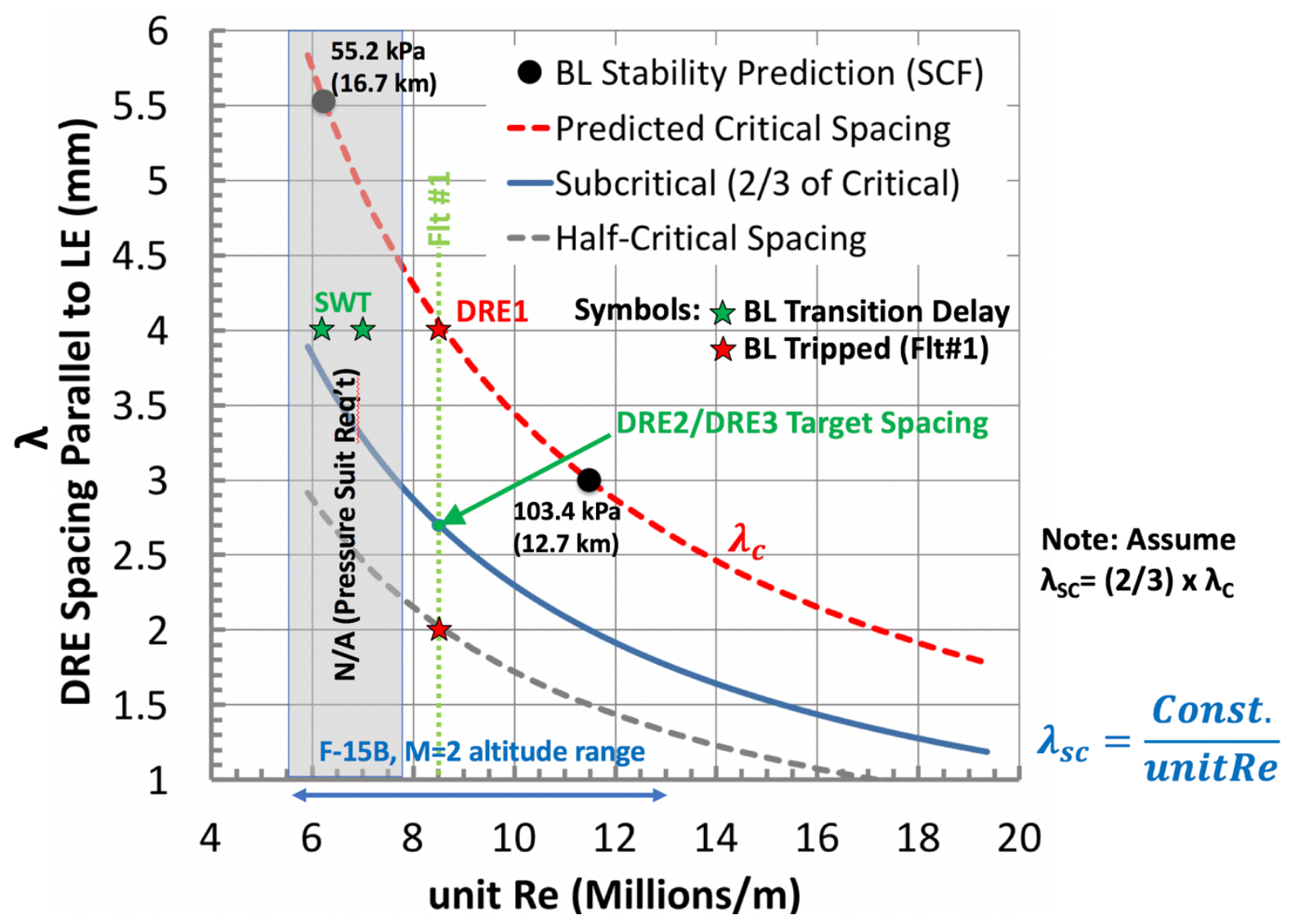

Fig. 11 Development of DRE spacing design map.
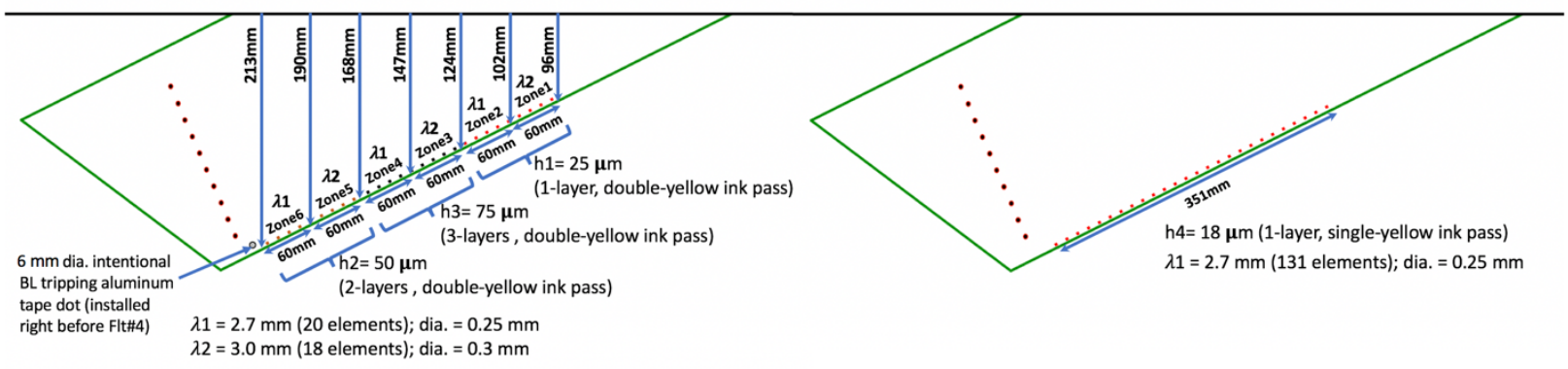

a) DRE2 pattern for height/spacing study.

b) DRE3 pattern for unsteady leading-edge pressures study.

Fig. 12 Flight testing DRE patterns. 


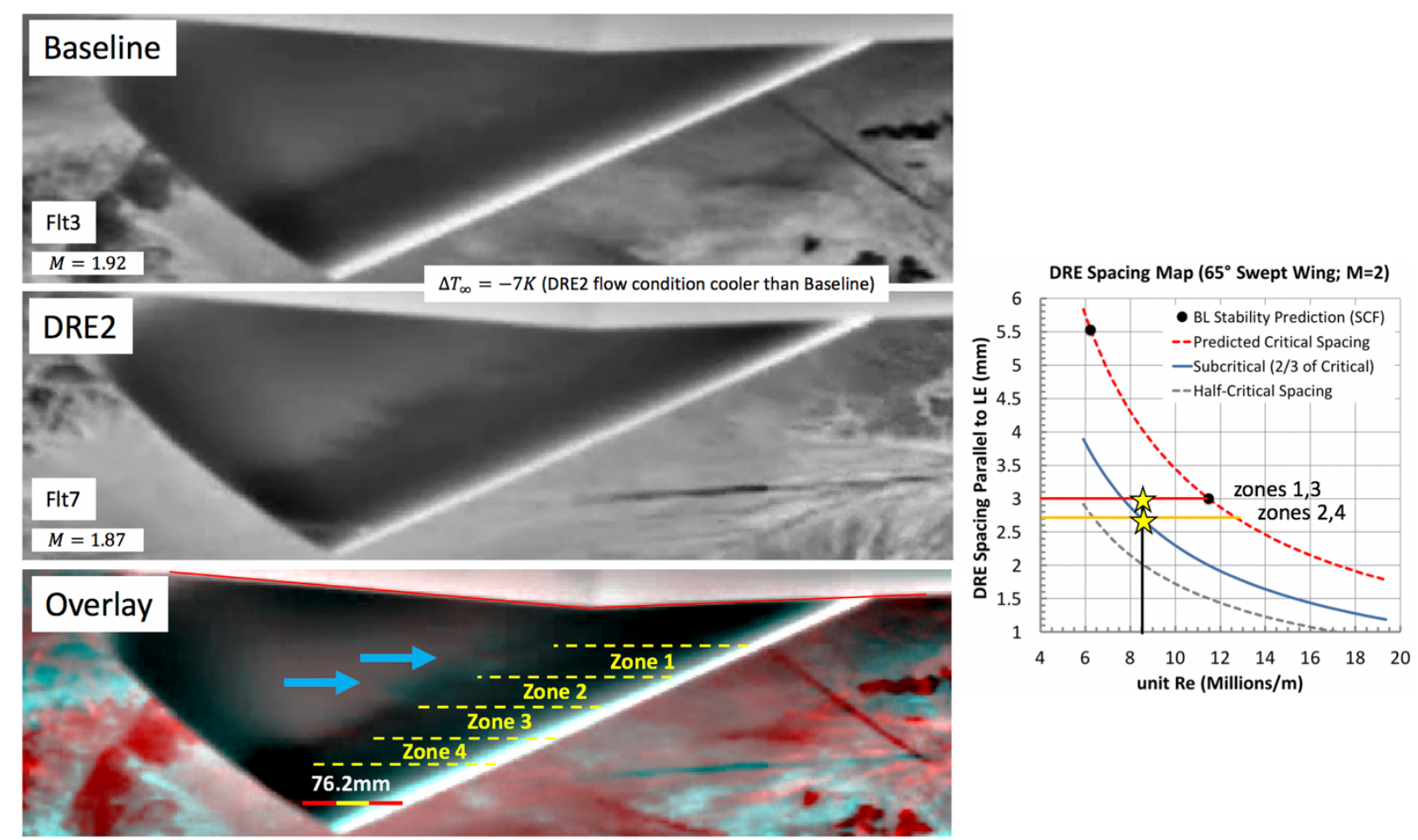

Fig. 13 Flight IR images showing DRE pattern control effect at unit $R e=8.5 \mathrm{million} / \mathrm{m}$.
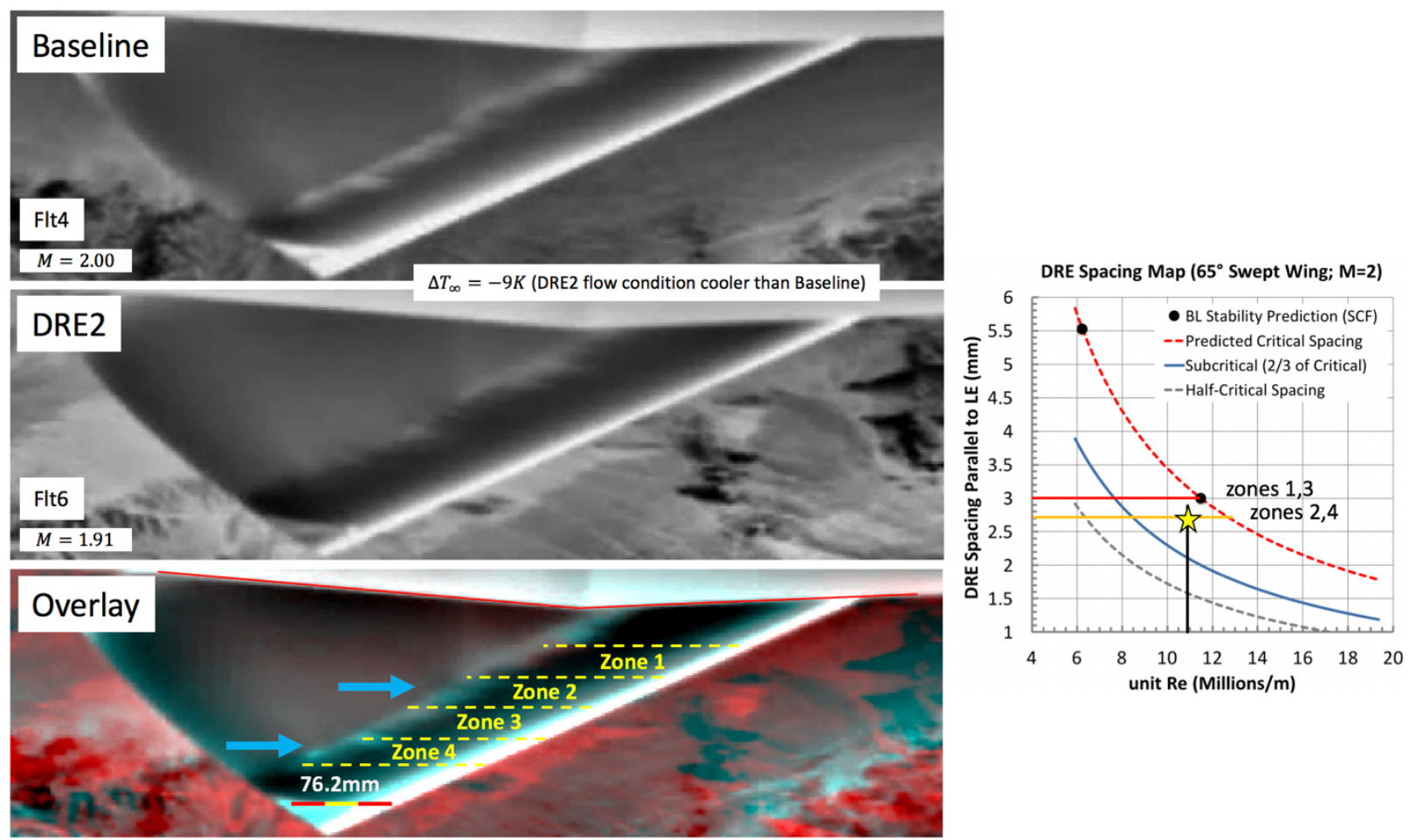

Fig. 14 Flight IR images showing DRE pattern control effect at unit $\operatorname{Re}=10.8 \mathrm{million} / \mathrm{m}$. 

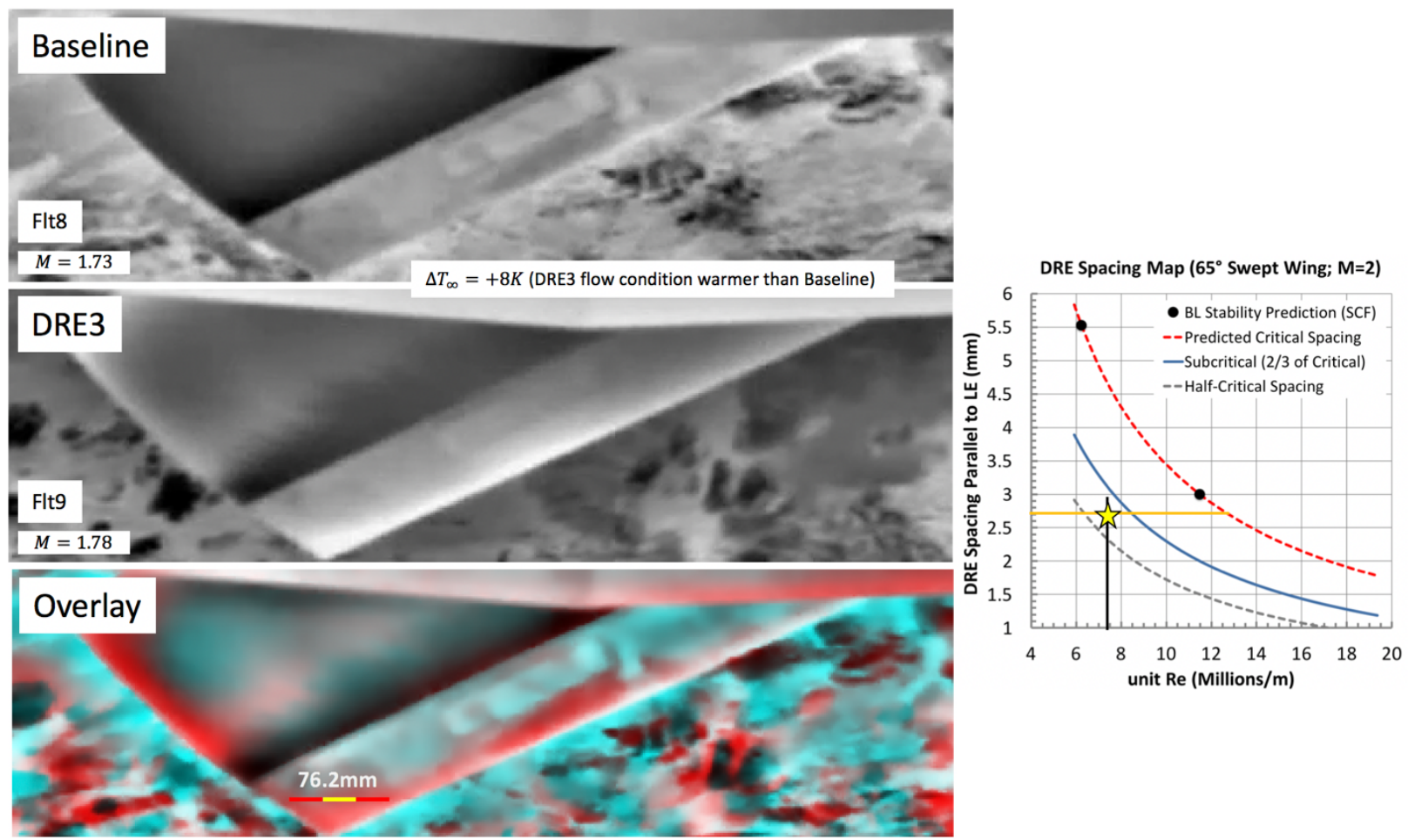

Fig. 15 Flight IR images showing DRE pattern control effect at unit $\operatorname{Re}=7.4 \mathrm{million} / \mathrm{m}$.

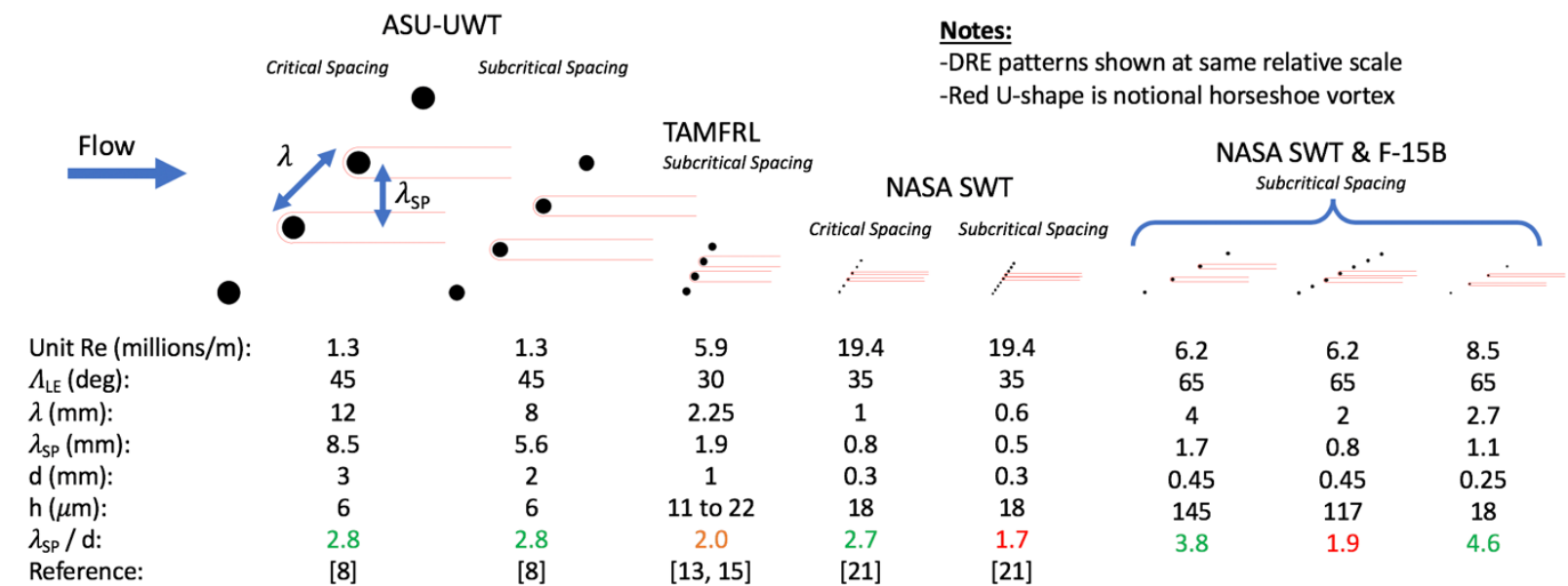

Fig. 15 Effective DRE pattern observations/insights. 


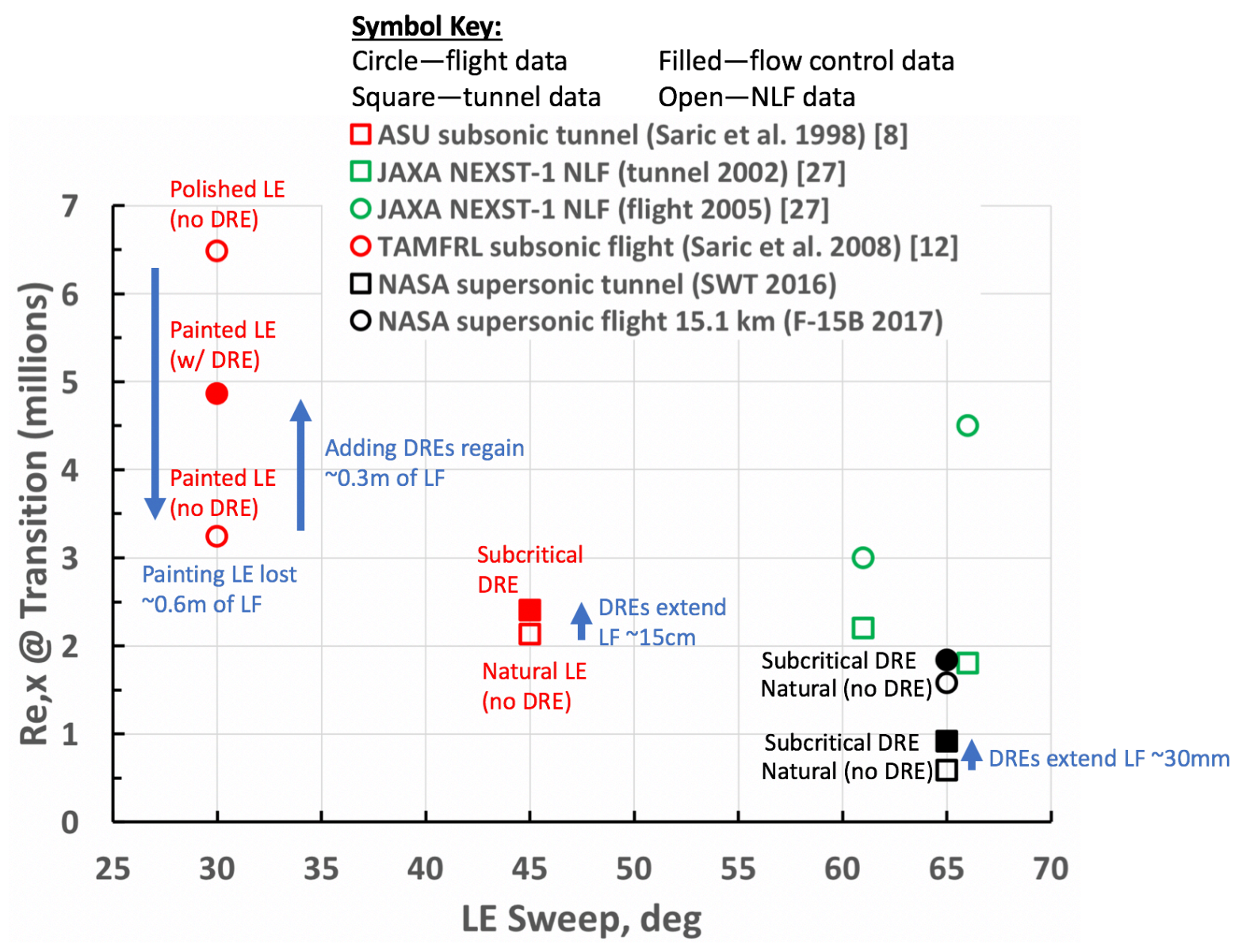

Fig. 16 Potential role of DRE technology as NLF protector.

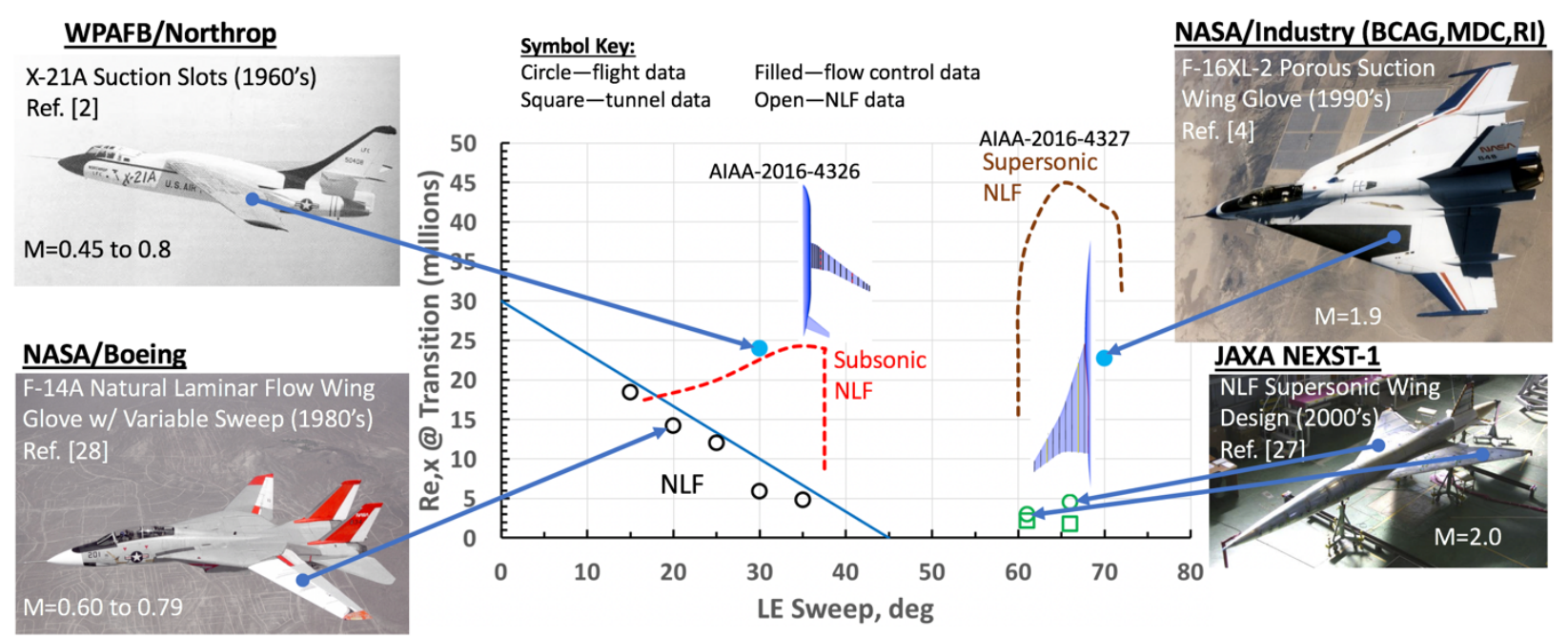

Fig. 17 Sampling of swept-wing research bigger picture (not all-inclusive). 